\title{
Determination of a non-perturbed reference for a new version of the disturbance ionosphere index
}

Giorgio Arlan da Silva Picanço ( $\square$ giorgio.picanco@inpe.br)

Instituto Nacional de Pesquisas Espaciais https://orcid.org/0000-0003-3926-396X

Clezio Marcos Denardini

Instituto Nacional de Pesquisas Espaciais

Paulo Alexandre Bronzato Nogueira

Federal Institute of Education, Science and Technology of São Paulo

Paulo França Barbosa-Neto

Instituto Nacional de Pesquisas Espaciais

Láysa Cristina Araújo Resende

Instituto Nacional de Pesquisas Espaciais

Carolina de Sousa do Carmo

Instituto Nacional de Pesquisas Espaciais

Esmeralda Romero-Hernandez

Universidad Autonoma de Nuevo Leon

Sony Su Chen

Instituto Nacional de Pesquisas Espaciais

Juliano Moro

Instituto Nacional de Pesquisas Espaciais

Regia Pereira da Silva

Instituto Nacional de Pesquisas Espaciais

Full paper

Keywords: TEC, DIX, lonospheric Indices, Space Weather

Posted Date: August 6th, 2020

DOI: https://doi.org/10.21203/rs.3.rs-51725/v1

License: (9) This work is licensed under a Creative Commons Attribution 4.0 International License.

Read Full License 


\section{Determination of a non-perturbed reference for a new version of the}

\section{2 disturbance ionosphere index}

3 Author \#1: Giorgio Arlan da Silva Picanço*, National Institute for Space Research,

4 12227-010, São José dos Campos - SP, Brazil, giorgio.picanco@inpe.br

5 Author \#2: Clezio Marcos Denardini, National Institute for Space Research, 12227-010,

6 São José dos Campos - SP, Brazil, clezio.denardin@inpe.br

7 Author \#3: Paulo Alexandre Bronzato Nogueira, Federal Institute of Education, Science

8 and Technology of São Paulo, Jacareí - SP, Brazil, paulo.nogueira@ifsp.edu.br

9 Author \#4: Paulo França Barbosa Neto, National Institute for Space Research,

10 12227-010, São José dos Campos - SP, Brazil, paulo.barbosa@inpe.br

11 Author \#5: Láysa Cristina Araújo Resende, State Key Laboratory of Space Weather,

12 NSSC/CAS, Beijing, China, and National Institute for Space Research, 12227-010, São

13 José dos Campos - SP, Brazil, laysa.resende@inpe.br

14 Author \#6: Carolina de Sousa do Carmo, National Institute for Space Research,

15 12227-010, São José dos Campos - SP, Brazil, carolina.carmo@inpe.br

16 Author \#7: Esmeralda Romero Hernandez, Universidad Autónoma de Nuevo León, 
17 Facultad de Ciencias Físico-Matemáticas, LANCE, Monterrey, Mexico,

18 esmeralda.romerohdz@uanl.edu.mx

19 Author \#8: Sony Su Chen, National Institute for Space Research, 12227-010, São José

20 dos Campos - SP, Brazil, sony.chen@inpe.br

21 Author \#09: Juliano Moro, State Key Laboratory of Space Weather, NSSC/CAS,

22 Beijing, China, and National Institute for Space Research, 12227-010, São José dos

23 Campos - SP, Brazil, julianopmoro@gmail.com

24 Author \#10: Regia Pereira da Silva, Northeast Regional Center - CRN/INPE,

25 59076-740, Natal - RN, Brazil, regia.pereira@inpe.br

26

27 *Corresponding author: INPE/DIDAE, Avenida dos Astronautas, 1758, Jardim da

28 Granja, 12227-010, São José dos Campos, SP, Brazil; Tel.: +55 12 3208-7155; E-mail:

29 giorgio.picanco@inpe.br; giorgiopicanco@gmail.com

30 


\section{Abstract}

32 In the present work, we propose and evaluate a new method for the determination of a

33 non-perturbed Total Electron Content (TEC) reference to apply it on a new version of

34 the disturbance ionosphere index (DIX). This method is based on the calculation of a

35 3-hour moving average over the TEC obtained during a given reference day (named

36 3hMAQd method). In this context, the reference day is supposed to represent a quiet

37 pattern considering geomagnetic and ionospheric features. To evaluate its performance,

38 we compared the proposed method with TEC values obtained from monthly medians

39 and the International Reference Ionosphere (IRI) model. The results are presented and

40 discussed in terms of a dispersion coefficient between each method and the averaged

41 TEC from the five quietest days of each month of 2015, over three Brazilian sites.

42 Finally, we calculated the new DIX based on our proposed method and compared it

43 with the original DIX values obtained during the extreme space weather event of St.

44 Patrick's Day magnetic storm (17-18 March 2015). Differences between the two DIX approaches are discussed to show the improvements in new DIX due to the application 
47 the DIX calculation can be highly influenced by the non-perturbed reference

48 determination. In this regard, the 3-hour moving average (3hMAQd) method showed to

49 be a quite appropriate technique for the new DIX calculation, besides the 3-hour

50 window matches with ordinary magnetic indices resolution (e.g. Kp and Ksa).

51

$52 \quad$ Keywords

53 TEC, DIX, Ionospheric Indices, Space Weather

54

\section{Introduction}

56 Ionospheric disturbances have a strong influence on the performance of radio-based

57 Global Navigation Satellite System (GNSS) (e.g. GPS, GLONASS, and Galileo). These

58 effects may include serious errors caused by rapid phase and amplitude fluctuations on

59 transionospheric radio signals, as well as interruptions in the satellite-receiver

60 connection due to loss of lock (Klobuchar, 1991; Jakowski et al., 2012a). In this

61 framework, ionospheric disturbances can be defined in terms of the abnormal variations

62 observed on values of TEC, being mainly related to phenomenon driven by solar 
63 eruptive/radiative events and/or associated with dynamical processes of the Earth's

64 atmosphere (Batista et al., 1991; Sobral et al., 1997; Abdu et al., 2006; Takahashi et al.,

65 2016). Thus, the use of planetary geomagnetic indices, such as AE and Dst is still

66 insufficient to represent the local ionospheric behavior as well as to detect ionospheric

67 disturbances (Jakowski et al., 2012b). Nevertheless, many efforts have been made to

68 develop indices that better represent the ionospheric response due to external and

69 internal drivers (e.g. Coronal Mass Ejections [CMEs], solar flares, and Medium Scale

70 Travelling Ionospheric Disturbances [MSTIDs]) (Denardini et al., 2020a, 2020b;

71 Jakowski and Hoque, 2019; Resende et al., 2019).

72 Denardini et al. (2020a) present a chronological list of some of the most well-known

73 ionospheric indices as well as a basic description of its calculation methodologies.

74 These methodologies have been developed aiming to provide a quick measure of the

75 abnormal ionospheric variations (e.g. TEC gradients due to ionospheric storms). Among

76 those listed indices, some ones have been constantly used as a practical way to measure

77 ionospheric disturbances based on well-established parameters, such as TEC. Also,

78 many examples using TEC-based ionospheric indices can be found in the literature 
79 (Gulyaeva and Stanislawska, 2008; Jakowski et al., 2006, 2012b; Sanz et al., 2014;

80 Voeykov et al., 2018; Wilken et al., 2018). Moreover, TEC-based ionospheric indices

81 are generally calculated from satellite data.

82 Starting from the concept of abnormal TEC variations, we consider that it is primarily

83 necessary to understand what a typical TEC variation is before to define a threshold for

84 an abnormal/disturbed behavior. With that in mind, we intend to make it clear the

85 differences between an ionospheric background value (non-perturbed TEC reference)

86 and a disturbed state value (variation concerning the non-perturbed reference). These

87 two parameters have been widely used in the study of ionospheric variations with

88 different time scales (Figueiredo et al., 2017, 2018a; Takahashi et al., 2018; Shinbori et

89 al., 2018; Tsugawa et al., 2018). Therefore, the proper definition of a non-perturbed

90 TEC reference is an essential matter to make sure that the index value is consistent with

91 what happens in the ionosphere.

92 With the aim to express the ionosphere response due to perturbations over a given

93 region, Jakowski et al. (2006) proposed the first formulation of a TEC-based parameter

94 named Disturbance Ionosphere indeX (DIX), which was obtained from GNSS data. 
95 Given this perspective, the DIX is based on the TEC variation over a background

96 calculated from TEC monthly medians, here referred to as a 'non-perturbed reference'.

97 The most important point of a non-perturbed reference is how well it can represent a

98 quiet pattern just considering geomagnetic and ionospheric features. This point is

99 essential because a non-perturbed reference must include TEC values related to the

100 expected behavior of a given day, excluding the ionospheric disturbances contribution

101 (considering those disturbances driven by external and/or internal sources). In this sense,

102 an inappropriate methodology for an ionospheric index can over/underestimate the real

103 behavior of the ionosphere by increasing/decreasing the TEC values during the

104 non-perturbed reference calculation.

105 Therefore, the main aims of this study are to propose and to evaluate a new method to

106 obtain the non-perturbed reference for a DIX formulation presented by Denardini et al.

107 (2020a) (here referred to as "new DIX"). We also intended to study different

108 approaches to represent the reference pattern as a function of temporal and spatial TEC

109 variations. Therefore, we demonstrate that the proposed method leads to an acceptable

110 reference for the new DIX by comparing it with some other methods, such as the one 
111 used by Jakowski et al. (2006), and another one defined by the use of TEC data

112 obtained from the IRI model (Bilitza et al., 2017). Those comparisons were performed

113 in terms of their similarities with the averaged TEC obtained from the five

114 geomagnetically quietest days of each month of the year 2015, determined by the

115 German Research Centre for Geosciences (GFZ). Additionally, we propose a dispersion

116 coefficient to evaluate the quality of each of the methods concerning the similarity with

117 the above-mentioned 5-days average. From that analysis, we select the proper method

118 for the new DIX non-perturbed reference calculation, for three Brazilian sites during the

119 year 2015. Finally, we calculated the new DIX values by using the proposed

120 non-perturbed reference over the period around the St. Patrick's Day magnetic storm

121 (17-18 March 2015) and compared it with the DIX values obtained from the original

122 methodology towards discussing the differences between both indices. The results

123 showed that the selected method is an adequate alternative to represent the new DIX

124 non-perturbed reference. 


\section{$127 \quad 2$ Methodology}

\section{$128 \quad 2.1$ Original DIX and new DIX indices}

129 The DIX is an ionospheric-disturbances index proposed in a first formulation by

130 Jakowski et al. (2006) and later evolved through the modification and inclusion of

131 various parameters (Jakowski et al., 2012a, 2012b, 2019; Wilken et al., 2018; Denardini

132 et al., 2020a). In its first formulation, the DIX was named Regional Ionosphere

133 Disturbances IndeX (RIDX), corresponding to a way of representing the ionospheric

134 degree of perturbation over a given region containing $n$ observations (piercing points).

135 Basically, the RIDX is based on the deviation of TEC values from a non-perturbed

136 reference obtained from TEC monthly medians. Thus, the index is defined in the

137 Equation (1) (Jakowski et al., 2006):

$$
\text { RIDX }_{\mathrm{r}}^{\text {med }}=\sqrt{\left(\frac{1}{\mathrm{~N}_{\text {grp }}-1}\right) \sum_{\mathrm{k}=1}^{\mathrm{N}_{\text {grp }}}\left(\left(\mathrm{TEC}_{\mathrm{k}}-\mathrm{TEC}_{\mathrm{k}}^{\mathrm{med}}\right) / \mathrm{TEC}_{\mathrm{k}}^{\mathrm{med}}\right)^{2}}
$$

141 where $\mathrm{TEC}_{\mathrm{k}}$ is the vertical TEC value obtained for a given piercing point $k=$

142 (latitude,longitude), $\mathrm{TEC}_{\mathrm{k}}^{\mathrm{med}}$ is the corresponding TEC monthly median, and $\mathrm{N}_{\text {grp }}$

143 is the number of observation points in the region of interest. 
144 In the present work, we used not an average of observation points over a region (see

145 Equation 1), but single-point vertical TEC data obtained from the TEC maps developed

146 at the "Brazilian Studies and Monitoring of Space Weather" (Embrace/INPE)

147 (Takahashi et al., 2016), which is a custom version of the earlier procedure presented by

148 Otsuka el al. (2002). Considering the use of single-point observations, we used the

149 RIDX equation modified by Denardini et al. (2020a) for only one observation point

150 (here referred to as original DIX), for comparison purposes. In this way, we compared

151 the "new DIX" values calculated using the proposed non-perturbed reference with the

152 “original DIX" values. The new DIX is defined by the Equation (2), as explained in

153 details by Denardini et al. (2020a):

154

$$
\operatorname{DIX}_{k}(t)=\sqrt{\left(\frac{\alpha\left(\Delta T E C_{k}(t) / T E C_{k}^{Q d}(t)\right)+\Delta T E C_{k}(t)}{\beta}\right)^{2}},
$$

156 where $T E C_{k}$ is the same term described in Equation (1), $T E C_{k}^{Q d}$ corresponds to the

157 non-perturbed reference value at a given time over the observation point. However,

$158 T E C_{k}^{Q d}$ differs from the $T E C_{k}^{\text {med }}$ since we are using the methodology proposed in this 
159 study. The term $\triangle T E C_{k}=\left|T E C_{k}(t)-T E C_{k}^{Q d}(t)\right|$ and the coefficient $\alpha$ (both given in

160 TEC units) intend to improve the new DIX sensitivity to internal drivers as well as to

161 normalize its response irrespective of the local time. Finally, the coefficient $\beta$ (also

162 given in TEC units) is chosen to normalize the DIX output into a scale ranging from 0

163 to 5. More details are given in Denardini et al., (2020a).

164 In view of the above, the comparison between two values derived from single piercing

165 points (original DIX and new DIX) is more appropriate for the non-perturbed reference

166 analysis since it mitigates effects due to spatial ionospheric variations. Therefore, the

167 main aim in the present work was to find an adequate methodology for representing the

168 non-perturbed reference, $\mathrm{TEC}_{\mathrm{k}}^{\mathrm{Qd}}$, as presented in the Equation (1).

\section{$170 \quad 2.2$ Determination of the reference day}

171 As proposed by Jakowski et al. (2006), monthly medians are a simple method to represent

172 a non-perturbed TEC reference. However, including data obtained during periods with

173 the occurrence of magnetic storms may lead the reference values to be contaminated with

174 a high-amplitude noise due to magnetic perturbation effects (e.g. positive/negative 
175 ionospheric storms due to prompt penetration, disturbance dynamo electric fields, and

176 thermospheric composition changes) (Kelley et al., 1979; Blanc and Richmond, 1980;

177 Wu et al., 2004; Abdu et al., 2006, Nogueira et al., 2011, de Siqueira, 2011). Thus, we

178 propose an alternative method to determine a non-perturbed reference for the new DIX.

179 The method is based on the use of a centered moving average of the TEC obtained during

180 a reference day along a period of interest of up to 15 days. This 2 -week window is set to

181 mitigate seasonal effects. In this regard, we define the reference day as the

182 geomagnetically quietest day of the period of interest where no plasma depletions greater

183 than 20 TEC units (TECU) along a period of 1 hour have been observed, and no spread-F

184 over a low-latitude station has been reported. We adopt this procedure once a day

185 considered geomagnetically quiet does not guarantee that it does not present disturbances

186 related to sources within the ionosphere (e.g. Equatorial Plasma Bubbles [EPBs] and

187 MSTIDs) (Takahashi et al., 2018; Figueiredo et al., 2018b). This criterion of 20 TEC

188 units is based on our experience with EPB studies in Brazil. With this in mind, the

189 geomagnetically quietest day is firstly selected from the list provided by GFZ Potsdam,

190 and the presence/absence of spread-F is posteriorly confirmed by observing ionograms 
191 from a low-latitude station (from 21:00 UT to 24:00 UT). In this sense, the reference day

192 is supposed to represent a quiet pattern considering geomagnetic and ionospheric

193 features.

194 An example of the method used to observe the occurrence of spread-F is presented in the

195 Figure 1, which provides a sequence of nine ionograms (virtual heights vs. reflection

196 frequencies) obtained from the ionosonde operating in Cachoeira Paulista (CPA,

$\left.19722.67^{\circ} \mathrm{S}, 44.99^{\circ} \mathrm{W}\right)$. These ionograms were obtained over the interval between 21:00 UT

198 and 23:30 UT on March 14, 2015. Observing the behavior of both ordinary and

199 extraordinary wave modes on the ionograms, we can clearly see that the occurrence of

200 spread-F was not reported (Abdu et al., 2009; Resende et al., 2019). Considering that the

201 daily sum of $\mathrm{Kp}$ is 10.67 , along with no observation of TEC depletions and spread-F, we

202 are able to state that 14 March can represent a reference day. Consequently, this reference

203 gathers characteristics of a quiet pattern considering geomagnetic and ionospheric

204 features. 


\subsection{Non-perturbed TEC reference calculation}

208 After these initial steps, the non-perturbed reference can be obtained by calculating a

209 centered moving average over the TEC data related to the above-mentioned reference

210 day. Therefore, our non-perturbed reference, MAQd, can be obtained using the

211 Equation (3):

212

$$
\operatorname{MAQd}(\mathrm{t})=\frac{1}{2 w+1} \sum_{\delta=-w}^{w} T E C(t+\delta)
$$

214

215 where $\operatorname{TEC}(t)$ is the TEC value at a given time, $t$, the term $\delta$ is the lower limit of the

216 moving average time scale (given in minutes), and $w$ is the point that should delimit

217 the sampling scale so that the non-perturbed reference value obtained has a position

218 equivalent to $T E C_{k}$ on the DIX equation.

220 The $w$ value is given by: 
$w= \begin{cases}(N-1) / 2, & \text { if } N \text { is odd } \\ (N / 2)-1, & \text { if } N \text { is even }\end{cases}$

222 where $N$ is the number of samples contained in the moving average window (e.g. for

22360 minutes, $N=60$ )

2253 Data Set and Evaluation of the Proposed Method

226 To empirically evaluate the efficacy of the proposed method in representing a

227 non-perturbed reference, we used the TEC values obtained from TEC maps at three

228 locations of GNSS stations in Brazil (single-points): São Luís (SLZ), São José dos

229 Campos (SJC), and Santa Maria (SMA). The geographic and geomagnetic coordinates

230 of the locations whose data were used in this study are given in Table 1. 
231 Figure 2 shows an example of the Embrace/INPE TEC map over South America

232 including the geographical locations of the three TEC single-points used in the present

233 work (SLZ, SJC, and SMA). The solid black line across the map represents the

234 magnetic equator in 2015.

236 Considering the Figure 2, we have chosen each of the three locations from the following

237 requirements:

238 - One site located in the neighborhood of the magnetic equator (SLZ);

239 - One site located nearby the Equatorial lonization Anomaly (EIA) southern crest

$240 \quad$ (SJC); and

241 - One site located south of the southern EIA crest (SMA).

242 In such a scenario, scattered locations around the EIA crest can provide different

243 viewpoints of the TEC behavior throughout the year (Takahashi et al., 2014). In this

244 way, we calculated the non-perturbed reference values for the year 2015 using the

245 proposed method. These calculations were made for the three sites within three different 
246 time scales: 1 hour (1hMAQd), 3 hours (3hMAQd), and 6 hours (6hMAQd). We

247 compared the non-perturbed series (1,3 and 6h-MAQd) with the TEC monthly medians

248 and with the TEC data provided by the IRI model, for the same period and same sites,

249 aiming to determine the best methodology for the non-perturbed TEC reference. These

250 comparisons were made from the determination of a similarity parameter between each

251 method and the average of the TEC obtained during the five geomagnetically quietest

252 days of each month (here referred as to "quiet TEC"), as an attempt to correlate each

253 reference TEC values with a geomagnetically quiet reference. In this context, we

254 assume that the non-perturbed reference for the new DIX must be similar to the

255 expected TEC curve during a geomagnetically quiet day, excluding plasma bubble

256 effects (see Session 2.2).

257 To calculate the above-mentioned similarity parameter, we propose a simple and useful

258 dispersion coefficient, $\chi$, given by the Equation (5):

259

$$
\chi=\sqrt{(1-a)^{2}+(1-r)^{2}}
$$


262 where $a$ is the slope of the linear regression between the TEC reference (MAQd,

263 Monthly Medians or TEC-IRI) and the quiet TEC measurements, and the term $r$ is the

264 Pearson's correlation coefficient between the same values.

265 Therefore, we have a simple parameter whose value corresponds to a single dispersion

266 coefficient. Thus, the closer to zero the $\chi$ value is, the closer the non-perturbed

267 reference TEC values are to the quiet TEC values, attesting to the quality of the method.

268 The opposite is also true. The higher the $\chi$ value is, the worse is the comparison with

269 the quiet TEC.

270

\section{Results and Discussions}

272 4.1 Non-perturbed references variation with respect to the reference day

273 Here we intend to compare the different non-perturbed references with their respective

274 reference days. In the case of the monthly medians, this comparison was performed with

275 TEC values for the whole month of 2015. Regarding TEC-IRI values and MAQd values,

276 the analysis considers the same reference day for the comparison.

277 Figure 3 displays an example of the time variation of non-perturbed TEC references 
278 calculated from each of the methods as described above. In this figure, each column

279 (with different colored lines) represents the time variation for each non-perturbed

280 reference method during February 2015 (black: monthly medians, red: TEC-IRI, blue:

281 1hMAQd, orange: 3hMAQd, and green: 6hMAQd), for the three TEC sites (from the

282 upper to the bottom panels: SLZ, SJC, and SMA). The TEC from the reference day is

283 represented by the gray curves. It is emphasized that each TEC monthly median is

284 calculated from all TEC values during each month (only February in this case).

285 Therefore, the left panel also shows all TEC curves from which the monthly medians

286 curve is obtained.

287 As shown in Figure 3, the monthly medians are calculated over TEC curves presenting

288 differences from each other from 15 TECU (around 07:00 UT) to 50 TECU (around

289 18:00 UT). This feature can be seen on the SLZ monthly median, where the measured

290 TEC curve's maximum value near 18:00 UT ranges from about 55 to 75 TEC units. In

291 the SJC monthly medians, it can be seen that the maximum daily TEC values are

292 ranging from 60 to 110 TEC units. Additionally, the TEC measured at SMA presents

293 maximum values ranging from 55 to 100 TEC units. Thus, TEC curves from SLZ and 
294 SMA show fewer amplitude variations than the SJC curves. It can also be seen a peak at

295 18:00 UT in the TEC measured at SJC on February 19 (yellow curve), being possibly an

296 electric field signature during a CME-driven geomagnetic storm with ionospheric

297 effects at low latitudes (Worku, 2019). In addition to these observations, it is reasonable

298 to say that the calculation of a non-perturbed reference based on monthly medians can

299 be highly influenced by TEC values obtained during days with the occurrence of

300 storm-related ionospheric disturbances.

301 Figure 3 also shows that TEC-IRI values tend to be similar to those on the reference day

302 only in the time interval between 00:00 UT to 12:00 UT but underestimate the values

303 over SJC and SMA in the early hours. These TEC values are quite different during other

304 times of the day. Indeed, TEC values closest to the reference day are observed in the

305 non-perturbed references calculated using the MAQd method. In this way, it is observed

306 that the 1hMAQd method provides a good smoothness of the reference day TEC

307 short-term time variations.

308 However, looking at the 3hMAQd curve we can observe that the short-time TEC

309 variations (less than 3 hours amplitude) are efficiently smoothed by this process. This 
aspect can be clearly observed at the SJC site panel, around 18:00 UT, where the double

311 peak in the reference day TEC is smoothed into a single one by the 3 hMAQd curve. The

312 same feature is not observed when the 1hMAQd method is used since the double peak

313 in TEC remains present. Since the TEC amplitude has not been significantly changed in

314 comparison to the reference day curve, such behavior is a good feature concerning the

315 improvement of the new DIX sensitivity to short time scale ionospheric phenomena (e.g.

316 Traveling Ionospheric Disturbances [TIDs]). As well as the 3hMAQd method, the

317 6hMAQd is also capable of smooth out short-term time variations. Nonetheless, the

318 6hMAQd tends to include significant amplitude differences in the non-perturbed

319 reference with respect to the reference day TEC, as can be seen from the SJC and SLZ

320 curves.

321

$322 \quad 4.2$ Analysis of the coefficients

323 Here we intend to compare the non-perturbed reference values obtained from the

324 different methods with the quiet TEC values, which are an average of the TEC obtained

325 during the five geomagnetically quietest days of a given month. Thus, Figure 4 displays 
326 the scatter plots of the non-perturbed references calculated from the monthly medians

327 (black symbols), TEC-IRI (red symbols), 1hMAQd (blue symbols), 3hMAQd (orange

328 symbols), and 6hMAQd (green symbols) at (a) SLZ, (b) SJC, and (c) SMA versus the

329 quiet TEC (qTEC) values obtained in February 2015, respectively.

330 Two features can be easily observed in Figure 4. The first one is that all non-perturbed

331 values related to qTEC values tend to be more dispersed on the TEC site located in the

332 EIA southern crest (SJC). This characteristic can be explained by the mechanism

333 described in Abdu (2005), who states that due to the increase (decrease) of the eastward

334 zonal electric field, the transport of plasma driven by the fountain effect is also

335 intensified (decreased) causing plasma from the EIA crest to be displaced towards

336 higher (lower) latitudes. Moreover, Abdu (2005) emphasizes the importance of the

337 thermospheric meridional wind for the position of the EIA crest. Thus, the EIA crest

338 behavior makes TEC at SJC to be more variable than others with respect to its

339 day-to-day variability. The other feature is that all methods have Pearson's correlation

340 coefficient values greater than 0.9. Thus, it is difficult to select a non-perturbed

341 reference method for the new DIX just considering the $r$ value. Therefore, we decided 
342 to select it from the results coming from the dispersion coefficient (see Equation 5).

343 The corresponding annual averages of the dispersion coefficient values for each

344 non-perturbed reference method are listed in Table 2. It is observed that the

345 non-perturbed reference method that comes closest to qTEC is the one obtained from

346 the calculation of a 1-hour moving average over the TEC obtained during the reference

347 day (1hMAQd). The monthly medians and the 3hMAQd methods are quite similar,

348 having even equal $\chi$-values for the SLZ site. However, it is emphasized that the

349 monthly medians may include both quiet and disturbed days in its calculation and so are

350 disregarded in the new DIX calculation (see results from May in Fig. 5). The other

351 methods (TEC-IRI and 6hMAQd) presented high $\chi$-values and therefore were also

352 disregarded. 
353 Figure 5 shows the annual variation of dispersion coefficient values calculated for each of

354 the methods. Each color represents the $\chi$-values monthly variation for each non-perturbed

355 reference method during the year 2015 (black: monthly medians, red: TEC-IRI, blue:

356 1hMAQd, orange: 3hMAQd, and green: 6hMAQd), for the three TEC sites (SLZ, SJC, 357 and SMA).

358 From Figure 5, it can be seen that the dispersion coefficient of the 1hMAQd method

359 presented low values ranging from 0 to about 0.2 for all TEC sites, attesting to the good

360 performance of the method. The 3hMAQd method presented dispersion values quite

361 similar to those obtained for the 1hMAQd method, along with the same consistency

362 during the year. The difference between the dispersion coefficients of these methods is

3630.03 , which shows that the use of the 3hMAQd method instead of 1hMAQd in the new

364 DIX calculation is not greatly affected. In respect to the monthly medians, the dispersion

365 coefficient presented inconstant values during January, April, and May, which confirms

366 that this method is strongly influenced by outliers. Moreover, the TEC-IRI and 6hMAQd

367 methods were disregarded because their dispersion coefficient values remained very high

368 throughout the entire period. 
369 Thus, the selected method for the determination of the new DIX non-perturbed reference

370 was the one represented by a 3-hour moving average over the TEC obtained during the

371 reference day. Thereafter, we calculate and validate the new DIX calculated from

372 Equation (2) by using the 3hMAQd method during the period around the St. Patrick's

373 Day magnetic storm.

374

$375 \quad 4.3$ Validation and application in a space weather event

376 The aim here is to present the ionospheric response during an extreme magnetic storm,

377 discussing the observed differences when applying the proposed method on the Equation

378 (2) and using the original DIX methodology, without giving too much emphasis to the

379 physical explanation for the ionospheric disturbances. Given this context, we have

380 chosen the St. Patrick's Day magnetic storm (17-18 March 2015) to discuss the observed

381 differences in the DIX values obtained from both methodologies. The temporal variations

382 of interplanetary and geophysical parameters during this intense geomagnetic storm are

383 detailed in Astafyeva et al. (2015). Figure 6 shows the new DIX time variation (panel 'a') 
superposed by the Dst index during the period from 16 to 21 March 2015, at the SJC TEC site. Furthermore, 14 March was chosen to be the reference day for the calculation of the 3hMAQd values. The panel ' $b$ ' presents the same parameters as on the previous panel,

387 but this time showing the original DIX time variation, where the non-perturbed reference 388 was obtained by the method of the monthly medians. It is important to mention that the 389 original DIX scale ranging from 0 to 2 was chosen to better observe the peaks of the 390 original method and to compare it with the new approach. At last, the panel 'c' presents 391 the time variation for the non-perturbed curves obtained from the 3hMAQd (red curve)

392 and Median (blue curve) methods, as well as the daily TEC variation (gray curve) related 393 to the studied period. Hatched rectangles identified by the numbers from 1 to 4 point out 394 time intervals on which this analysis is focused.

395 Throughout this period of study, the Dst index values remained close to zero on 16 396 March. However, on 17 March the occurrence of an extreme magnetic storm caused the 397 Dst index value to decrease to about -223 nT during the magnetic storm main phase, 398 which lasted until near 00:00 UT on 18 March. It is also noteworthy that this event is 399 known as the St. Patrick's Day magnetic storm and its effects on the ionosphere have 
400 been constantly studied (Astafyeva et al., 2015; Wu et al., 2016; Venkatesh et al., 2017;

401 Barbosa et al., 2018). Regarding the time evolution of this space weather event, the storm

402 recovered on 25 March, with Dst index values approaching zero around 13:00 UT

403 (Venkatesh et al., 2017; Maurya et al., 2018).

404 It should be noted that the new DIX detected the occurrence of ionospheric disturbances

405 during almost all the period, while these responses presented some inconsistencies when

406 observed in the original DIX values. For instance, on 16 March around 00:00-09:00 UT

407 we can see that the new DIX presented two periodic peaks ranging between scales 1 and 2

408 (hatched area 1), which is barely observed by the original DIX. These disturbances are

409 strongly associated with the occurrence of Spread F in the pre-storm period (see

410 ionograms in Figure 7). Hence, while the new DIX presented a clear and periodic

411 behavior in detecting the Spread F TEC response, the original DIX presented a noisy

412 behavior, not unlike the one observed throughout the entire daily variation for 16 March. 
414 On the 17th, during the storm main phase, it can be observed in both DIX methodologies

415 a slight disturbance between 14:00 UT, which extends to 10:00 UT on the 18th. These

416 peaks are directly associated with TEC increases related to the storm-related Prompt

417 Penetration Electric Field (PPEF) occurrence in low latitudes (Venkatesh et al., 2017).

418 Regarding the daytime TEC increases due to PPEF, both indices had a similar response.

419 However, it can be seen that the original DIX tended to overestimate nighttime TEC

420 increases (vertical line ' 3 '), which may be a direct consequence of the original DIX

421 equation, which considers a percentage variation in its calculation. In contrast, the

422 original DIX presented a quite progressive behavior during the PPEF occurrence,

423 gradually increasing its value to the level 5 (extremely disturbed state), and then

424 decreasing until it returned to near zero (quiet state) while the electric field became less

425 effective in disturbing the TEC.

426 Other indications of overestimation in the original DIX nighttime ionospheric response

427 can also be seen on the 19th and 20th (hatched areas 4 and 5, respectively), where the

428 difference between the measured daily TEC and the median-based reference is clearly

429 smaller at night, however, the index shows higher values. The same is not seen in the new 
430 DIX values, which show a response consistent with the difference between the measured

431 daily TEC and the 3hMAQd reference, irrespective of the period of the day.

\section{Conclusions}

434 In this paper, we proposed and evaluated a new method to determine the non-perturbed

435 TEC reference for the new DIX as it was described in Denardini et al., (2020a). The

436 conclusions are summarized below:

437

1. Monthly medians can be highly influenced by TEC values obtained during

such a method. geomagnetically disturbed days since its dispersion coefficient presented inconstant values in January, April, and May. This behavior confirms that this method is strongly influenced by outliers, and the authors recommend not using 
was disregarded because its dispersion coefficient values remained very high throughout the entire period of study.

3. All non-perturbed TEC references tend to be more dispersed (concerning the qTEC values) on the site located near the EIA southern crest (SJC).

4. The non-perturbed TEC reference method that comes closest to qTEC is the one obtained from the calculation of a 1-hour moving average over the TEC obtained during the reference day (1hMQd). However, the 3hMAQd method is a better way to improve the new DIX sensitivity to short time scale ionospheric phenomena. The difference between the dispersion coefficients of these methods is 0.03 , which shows that the use of the 3hMAQd method instead of 1hMAQd in the new DIX calculation is not greatly affected. Also, both methods demonstrated to have stable dispersion coefficients along the whole year of analysis. response to magnetic storms than the original DIX, which uses monthly medians. 


\section{Declarations}

465

466 Ethics approval and consent to participate

467 Not applicable.

468

469 Consent for publication

$470 \quad$ Not applicable.

471

472 List of abbreviations

473

474 Availability of data and materials 
475 The data used in the present study are fully open and accessible in acknowledgment

476 basis at the Embrace/INPE Program website (http://www.inpe.br/spaceweather).

\section{Competing interests}

479 The authors declare that they have no competing interests.

480

$481 \quad$ Funding

482 This study was financed in part by the Coordenação de Aperfeiçoamento de Pessoal de

483 Nível Superior - Brasil (CAPES) - Finance Code 001.

484

485

486 Authors' contributions

487 G. A. S. Picanço conceived the study, designed the data analysis, and leaded writing this

488 manuscript.

489 C. M. Denardini assisted to conceive the study, design and process the data analysis, as

490 well as to discuss the results of the study.

491 P. A. B. Nogueira assisted to conceive the study, design and process the data analysis, as

492 well as to discuss the results of the study. 
493 P. F. Barbosa Neto performed the GNSS data processing, developed codes for the DIX

494 calculation and some of the data analysis.

495 L. C. A. Resende assisted to design the study and to perform the ionosonde data 496 analysis.

497 C. S. Carmo assisted with the computational codes for data processing and to discuss 498 the results of the study.

499 E. Romero Hernandez developed/adapted the computational codes for GNSS data 500 processing, and assisted to review the manuscript and to discuss the results of the study.

501 S. S. Chen helped with computational codes for data processing and assisted to review

502 the manuscript and to discuss the results of the study.

503 J. Moro assisted to review the manuscript and discuss the results of the study.

504 R. P. Silva assisted to review the manuscript and discuss the results of the study.

505 All the authors helped to write and revise this manuscript.

506

507 Acknowledgements

508 The authors thank the Embrace/INPE Space Weather Program for providing the TEC

509 data, the IBGE for providing the raw TEC data, and the DIDAE/INPE for providing the 
510 ionosonde data to Embrace/INPE. G. A. S. Picanço thanks CNPq/MCTIC (Grant

511 132252/2017-1) and Capes/MEC (Grant 88887.351778/2019-00). C. M. Denardini

512 thanks CNPq/MCTIC (Grant 303643/2017-0). P. F. Barbosa Neto thanks Capes/MEC

513 (Grant 1622967). L C. A. Resende would like to thank the China-Brazil Joint

514 Laboratory for Space Weather (CBJLSW), National Space Science Center (NSSC),

515 Chinese Academy of Sciences (CAS) for supporting her postdoctoral fellowship. C. S.

516 Carmo thanks CNPq/MCTIC for supporting her Ph.D (Grant 141935/2020-0). S. S.

517 Chen thanks CNPq/MCTIC (Grant 134151/2017-8) and Capes/MEC (Grant

518 88887.362982/2019-00). J. Moro thanks the China-Brazil Joint Laboratory for Space

519 Weather (CBJLSW), NSSC/CAS for supporting his postdoctoral fellowship, and the

520 National Council for Scientific and Technological Development (CNPq) for the grant

521 429517/2018-01. R. P. Silva thanks CNPq/MCTIC (Grant 300986/2020-3).

522

\section{Authors' information}

524 Affiliations

525 National Institute for Space Research - INPE, Aeronomy Division, São José dos

526 Campos, Brazil

527 Giorgio Arlan da Silva Picanço, Clezio Marcos Denardini, Paulo França Barbosa Neto, 528 Carolina de Sousa do Carmo \& Sony Su Chen

529 Northeast Regional Center - CRN/INPE, Natal, Brazil

$530 \quad$ Régia Pereira da Silva 
531 National Space Science Center, China Academy of Science - NSSC/CAS, Beijing,

532 China

533 Láysa Cristina Araújo Resende \& Juliano Moro

534 Federal Institute of Education, Science and Technology of São Paulo - IFSP,

535 Jacareí, Brazil

536 Paulo Alexandre Bronzato Nogueira

537 Universidad Autónoma de Nuevo León, Facultad de Ciencias Físico-Matemáticas -

538 UANL/FCFM, Monterrey, Mexico

539 Esmeralda Romero Hernández

540

\section{$541 \quad$ References}

542 Abdu, M. A. (2005), Equatorial ionosphere-thermosphere system: electrodynamics and

543 irregularities, Advances in Space Research, 35, 771-787, doi:10.1016/j.asr.2005.03.150.

544 Abdu, M. A., de Souza, J. R., Sobral, J. H. A., and Batista, I. S. (2006), Magnetic storm

545 associated disturbance dynamo effects in the low and equatorial latitude ionosphere,

546 Geophysical Monograph Series, 167, 283-304, doi:10.1029/167GM22.

547 Abdu, M. A., Batista, I. S., Reinisch, B., de Souza, J., Sobral, J. H. A., Pedersen, T.,

548 Medeiros, A., Schuch, N., de Paula, E., Groves, K. (2009), Conjugate Point Equatorial 
549 Experiment (COPEX) Campaign in Brazil: Electrodynamics highlights on spread F

550 development conditions and day-to-day variability, Journal of Geophysical Research:

$551 \quad$ Space Physics, 114(4), doi:10.1029/2008JA013749.

552 Astafyeva, E., Zakharenkova, I., and Förster, M. (2015), Ionospheric response to the

5532015 St. Patrick's Day storm: a global multi-instrumental overview, Journal of

554 Geophysical Research, 120, 9023-9037, doi:10.1002/2015JA021629.

555 Barbosa, F. R. E., Fagundes, P. R., Venkatesh, K., Fejer, B. G, Pillat, V. G., Denardini, C.

556 M., Muella, M. T. A. H. (2018), Multi-scale ionospheric irregularities occurrence over

557 South America during the St. Patrick's day storm on March 17, 2015, Journal of

558 Atmospheric and Solar-Terrestrial Physics, 174, 32-45, doi:10.1016/j.jastp.2018.05.001.

559 Batista, I. S., de Paula, E. R., Abdu, M. A., Trivedi, N. B., and Greenspan, M. E. (1991),

560 Ionospheric effects of the March 13, 1989, magnetic storm at low and equatorial

561 latitudes, Journal of Geophysical Research: Space Physics, 96(A8), 13943-13952.

562 doi:10.1029/91ja01263.

563 Bilitza, D., Altadill, D., Truhlik, V., Shubin, V., Galkin, I., Reinisch, B., and Huang, X.

564 (2017), International Reference Ionosphere 2016: From ionospheric climate to real-time

565 weather predictions, Space Weather, 15(2), 418-429, doi:10.1002/2016SW001593.

566 Blanc, M., and Richmond, A. D. (1980), The ionospheric disturbance dynamo, Journal

567 of Geophysical Research, 85, 1669-1669, doi:10.1029/JA085iA04p01669. 
568 Denardini, C. M., Picanço, G. A. S., Barbosa Neto, P. F., Nogueira, P. A. B., Carmo, C.

569 S., Resende, L. C. A., Moro, J., Chen, S. S., Romero-Hernandez, E., Silva, R. P., and

570 Bilibio, A. V. (2020a), Ionospheric Scale Index Map Based on TEC Data for Space

571 Weather Studies and Applications, Space Weather, Accepted manuscript

572 2019SW002328RRR.

573 Denardini, C. M., Picanço, G. A. S., Barbosa Neto, P. F., Nogueira, P. A. B., Carmo, C.

574 S., Resende, L. C. A., Moro, J., Chen, S. S., and Bilibio, A. V. (2020b), ), Ionospheric

575 Scale Index Map Based on TEC Data during the Saint Patrick Magnetic Storms and

576 EPBs, Space Weather, Accepted manuscript 2019SW002330RRR.

577 de Siqueira, P. M., de Paula, E. R., Muella, M. T. A. H., Rezende, L. F. C., Abdu, M. A.,

578 and Gonzalez, W. D. (2011), Storm-time total electron content and its response to

579 penetration electric fields over South America, Annales Geophysicae, 29, 1765-1778,

580 doi:10.5194/angeo-29-1765-2011.

581 Figueiredo, C. A. O. B., Wrasse, C. M., Takahashi, T., Otsuka, Y., Shiokawa, K., and

582 Barros, D. (2017), Large-scale traveling ionospheric disturbances observed by GPS

583 dTEC maps over North and South America on Saint Patrick's Day storm in 2015,

584 Journal of Geophysical Research: Space Physics, 122, 4755-4763,

585 doi:10.1002/2016JA023417.

586 Figueiredo, C. A. O. B., Takahashi, H., Wrasse, C. M., Otsuka, Y., Shiokawa, K., and 587 Barros, D. (2018a), Medium-scale traveling ionospheric disturbances observed by 
588 detrended total electron content maps over Brazil, Journal of Geophysical Research: 589 Space Physics, 123, 2215-2227, doi:10.1002/2017JA025021.

590 Figueiredo, C. A. O. B., Takahashi, H., Wrasse, C. M., Otsuka, Y., Shiokawa, K., and

591 Barros, D. (2018b), Investigation of nighttime MSTIDS observed by optical

592 thermosphere imagers at low latitudes: Morphology, propagation direction, and wind

593 filtering, Journal of Geophysical Research: Space Physics, 123, 7843-7857,

594 doi:10.1029/2018JA025438.

595 Gulyaeva, T. L., and Stanislawska, I. (2008), Derivation of a planetary ionospheric 596 storm index, Annales Geophysicae, 26(9), 2645-2648, 597 doi:10.5194/angeo-26-2645-2008.

598 Jakowski, N., Stankov, S. M., Schlueter, S., and Klaehn, D. (2006), On developing a 599 new ionospheric perturbation index for space weather operations, Advances in Space 600 Research, 38, 2596-2600, doi:10.1016/j.asr.2005.07.043.

601 Jakowski, N., Béniguel, Y., De Franceschi, G., Pajares, M. H., Jacobsen, K. S.,

602 Stanislawska, I., Tomasik, L., Warnant, R., and Wautelet, G. (2012a), Monitoring, 603 tracking and forecasting ionospheric perturbations using GNSS techniques, Journal of 604 Space Weather and Space Climate, 2, doi:10.1051/swsc/2012022.

605 Jakowski, N., Borries, C., and Wilken, V. (2012b), Introducing a disturbance ionosphere 606 index, Radio Science, 47(3), doi:10.1029/2011RS004939. 
607 Jakowski, N., and Hoque, M. M. (2019), Estimation of spatial gradients and temporal

608 variations of the total electron content using ground-based GNSS measurements, Space

609 Weather, 17, 339-356, doi:10.1029/2018SW002119.

610 Kelley, M. C., Fejer, B. G., and Gonzales, C. A. (1979), An explanation for anomalous

611 ionospheric electric fields associated with a northward turning of the interplanetary

612 magnetic field, Geophysical Research Letters, 6, 301-304,

613 doi:10.1029/GL006i004p00301.

614 Klobuchar, J. A. (1991), Ionospheric effects on GPS, GPS World, 2(4), 48-51.

615 Maurya, A. K., Venkatesh, K., Kumar, S., Singh, R., Tiwari, P., Singh, A. K. (2018),

616 Effects of St. Patrick's day geomagnetic storm of March 2015 and of June 2015 on

617 low-Equatorial D region ionosphere, Journal of Geophysical Research, 123, 6836-6850,

618 doi: $10.1029 / 2018 J A 0255361$.

619 Nogueira, P. A. B., Abdu, M. A., Batista, I. S., and de Siqueira, P.M. (2011), Equatorial 620 ionization anomaly and thermospheric meridional winds during two major storms over

621 Brazilian low latitudes, Journal of Atmospheric and Solar-Terrestrial Physics, 73, 622 1535-1543, doi: 10.1016/j.jastp.2011.02.008.

623 Otsuka, Y., Ogawa, T., Saito, A., Tsugawa, T., Fukao, S., Miyazaki, S. (2002), A new 624 technique for mapping of total electron content using GPS network in Japan, Earth 625 Planets Space, 54, 63-70, doi: 10.1186/BF03352422. 
626 Resende, L. C. A., Denardini, C. M., Picanço, G. A. S., Moro, J., Barros, D., Figueiredo, 627 C. A. O. B., and Silva, R. P. (2019). On developing a new ionospheric plasma index for 628 the Brazilian equatorial F region irregularities. Annales Geophysicae, 37, 807-818, doi: 629 10.5194/angeo-37-807-2019.

630 Sanz, J., Juan, J. M., González-Casado, G., Prieto-Cerdeira, R., Schlüter, S., Orús, R.

631 (2014), Novel Ionospheric Activity Indicator Specifically Tailored for GNSS Users,

632 Proceedings of the 27th International Technical Meeting of the Satellite Division of The 633 Institute of Navigation (ION GNSS+ 2014), Tampa, Florida, September 2014, $634 \quad 1173-1182$.

635 Shinbori, A., Otsuka, Y., Tsugawa, T., Nishioka, M., Kumamoto, A., Tsuchiya, F., 636 Matsuda, S., Kasahara, Y., Matsuoka, A., Ruohoniemi, J. M., Shepherd, S. G., and 637 Nishitani, N. (2018), Temporal and spatial variations of storm time midlatitude 638 ionospheric trough based on global GNSS-TEC and Arase satellite observations, 639 Geophysical Research Letters, 45, 7362-7370, doi:10.1029/2018GL078723.

640 Sobral, J. H. A., Abdu, M. A., Gonzalez, W. D., Tsuturani, B. T., Batista, I. S., and 641 Gonzalez, A. L. (1997), Effects of intense storms and substorms on the equatorial 642 ionosphere/thermosphere system in the American sector from ground-based and satellite 643 data, Journal of Geophysical Research: Space Physics, doi:10.1029/97JA00576.

644 Takahashi, H., Costa, S., Otsuka, Y., Shiokawa, K., Monico, J. F. G., Paula, E., Nogueira, 645 P., Denardini, C. M., Becker-Guedes, F., Wrasse, C. M., Ivo, A. S., Gomes, V. C. F., 
646 Gargarela, W., Sant'Anna, N., and Gatto, R. (2014), Diagnostics of equatorial and low

647 latitude ionosphere by TEC mapping over Brazil, Advances in Space Research, 54(3),

648 385-394, doi: 10.1016/j.asr.2014.01.032.

649 Takahashi, H., Wrasse, C. M., Denardini, C. M., Pádua, M. B., de Paula, E. R., Costa, S.

650 M. A., Otsuka, Y., Shiokawa, K., Galera Monico, J. F., Ivo, A., and Sant'Anna, N.

651 (2016), Ionospheric TEC Weather Map Over South America, Space Weather, 14(11),

652 937-949, doi:10.1002/2016SW001474.

653 Takahashi, H., Wrasse, C. M., Figueiredo, C. A. O. B., Barros, D., Abdu, M. A., Otsuka,

654 Y., and Shiokawa, K. (2018), Equatorial plasma bubble seeding by MSTIDs in the

655 ionosphere, Progress in Earth and Planetary Science, 5:32,

656 doi:10.1186/s40645-018-0189-2.

657 Tsugawa, T., Nishioka, M., Ishii, M., Hozumi, K., Saito, S., Shinbori, A., Otsuka, Y.,

658 Saito, A., Buhari, S., Abdullah, M. and Supnithi, P. (2018), Total Electron Content

659 Observations by Dense Regional and Worldwide International Networks of GNSS,

660 Journal of Disaster Research, 13(3), 535-545, doi: 10.20965/jdr.2018.p0535.

661 Venkatesh, K.; Tulasi Ram, S.; Fagundes, P. R.; Seemala, G. K.; Batista, I. S.

662 Electrodynamic disturbances in the Brazilian equatorial and low-latitude ionosphere on

663 St. Patrick's Day storm of 17 March 2015. Journal of Geophysical Research: Space

664 Physics, v. 122, p. 4553-4570, 2017.

665 Voeykov, S. V., Yasyukevich, A. S., Edemskiy, I. K., Perevalova, N. P., and Yasyukevich, 
666 Y. V. (2018), WTEC: A new index to estimate the intensity of ionospheric disturbances,

667 Results in Physics, 11, 1056-1057, doi:10.1016/j.rinp.2018.11.023.

668 Wilken, V., Kriegel, M., Jakowski, N., and Berdermann, J. (2018), An ionospheric index

669 suitable for estimating the degree of ionospheric perturbations, Journal of Space

670 Weather and Space Climate, 8(A19), doi:10.1051/swsc/2018008.

671 Wu, C. C., Fry, C. D., Liu, J. Y., Liou, K., and Tseng, C. L. (2004), Annual TEC

672 variation in the equatorial anomaly region during the solar minimum: September 1996-

673 August 1997, Journal of Atmospheric and Solar-Terrestrial Physics, 66, 199-207, doi:

$674 \quad$ 10.1016/j.jastp.2003.09.017.

675 Wu, C., Liou, K., Lepping, R., Hutting, L., Plunkett, S., Howard, R., and Socker, D.

676 (2016), The first super geomagnetic storm of solar cycle 24: “The St. Patrick's day

677 event (17 March 2015)”, Earth, Planets and Space, 68(1),

678 doi:10.1186/s40623-016-0525-y.

679

680

681

682

683

684

685 
686 Figure captions

687 Figure 1 - Sequence of ionograms from 21:00 UT to 22:20 UT on March 14, 2015,

688 demonstrating the absence of spread-F over Cachoeira Paulista.

689 Figure 2 - TEC map on 14 March, 2015 showing the geographic locations of the three

690 TEC single-points used in this study: SLZ, SJC, SMS.

691 Figure 3 - Time variation of non-perturbed TEC references calculated from each of the

692 methods (black lines: monthly medians, red lines: TEC-IRI, blue lines: 1hMAQd,

693 orange lines: 3hMAQd, and green lines: 6hMAQd), for the three TEC sites (SLZ, SJC,

694 and SMA) on February 2015, from the TEC measurements (gray lines).

695 Figure 4 - Scatter plots of the non-perturbed references calculated from the monthly

696 medians (black symbols), TEC-IRI (red symbols), 1hMAQd (blue symbols), 3hMAQd

697 (orange symbols), and 6hMAQd (green symbols) at (a) SLZ, (b) SJC , and (c) SMA

698 against the qTEC values in March 2015, respectively.

699 Figure 5 - Annual variation of dispersion coefficient values related to the monthly

700 medians (black squares), TEC-IRI (red cyrcles), 1hMAQd (blue diamonds), 3hMAQd

701 (orange hexagons), and 6hMAQd (green stars) at (a) SLZ, (b) SJC, and (c) SMA during 702 the year 2015.

703 Figure 6 - Time variation of (panel 'a') new DIX and (panel 'b') original DIX,

704 superposed by the Dst index, and non-perturbed references (panel 'c') used for their

705 calculation along with the daily TEC during the period around the St. Patrick's Day

706 magnetic storm.

707 Figure 7 - Sequence of ionograms from 01:30 UT to 02:50 UT on March 16, 2015, 
708 demonstrating the presence of spread-F over Cachoeira Paulista (same SJC observation 709 point). Black arrows indicate spread of the signal.

710

711

712

713

714

715

716

717

718

719

720

721

722

723

724

725

726

727

728

729 


\section{Table captions}

731 Table 1 - Geographic and geomagnetic coordinates of the three locations used in this

732 study.

733 Table 2 - Annual average of dispersion coefficient values obtained for each

734 non-perturbed reference method at the three TEC sites, for the year 2015.

735

736

737

738

739

740

741

742

743

744

745

746

747

748

749

750

751 
753
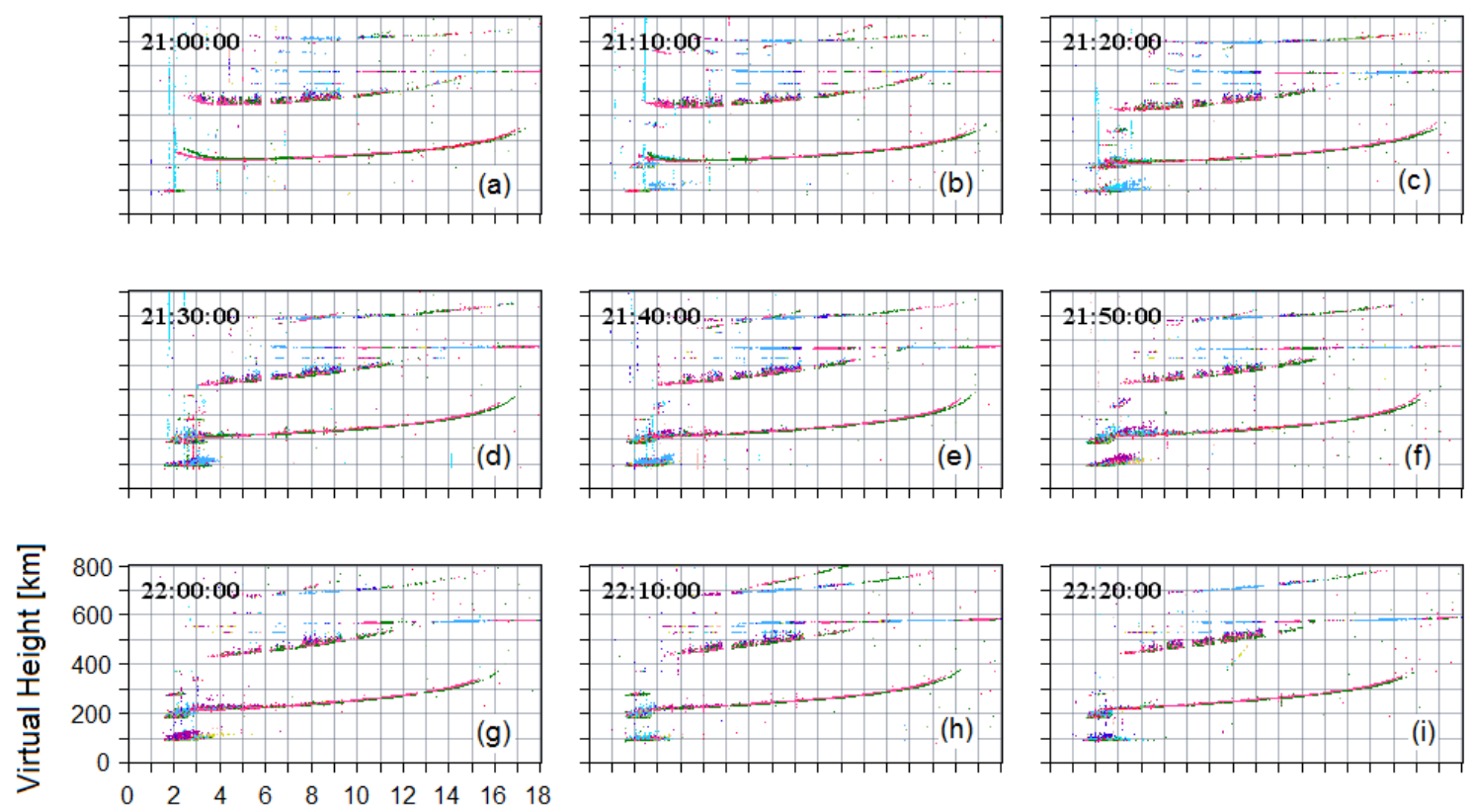

754

Frequency $[\mathrm{MHz}]$

755

756

757

758

759

760

761

762

763

764

765 
766

767

768

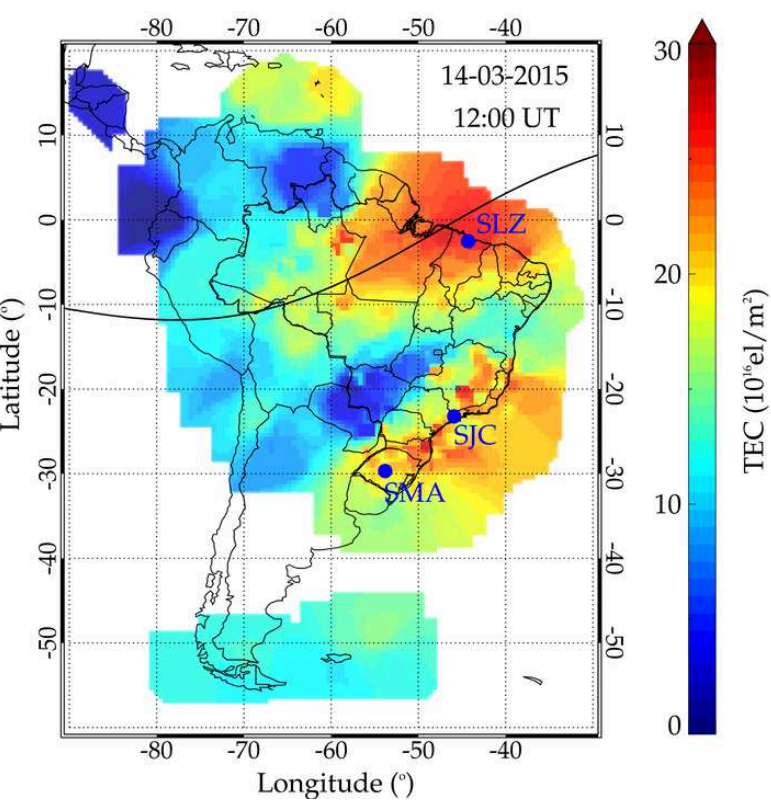

769

770

771

772

773

774

775

776

777

778

779

780 
782
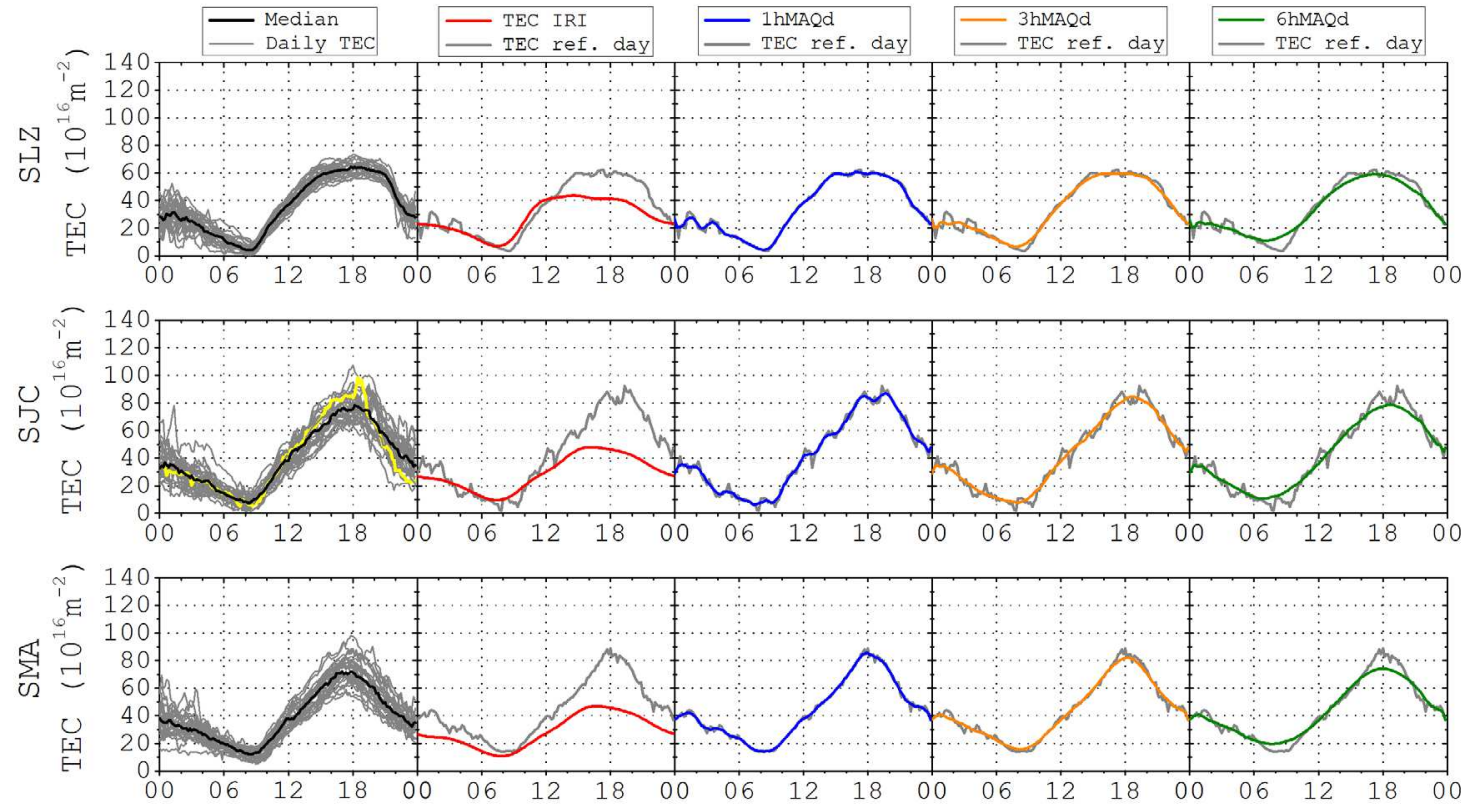

783

Universal Time (UT=LT+03)

784

785

786

787

788

789

790

791

792

793

794 

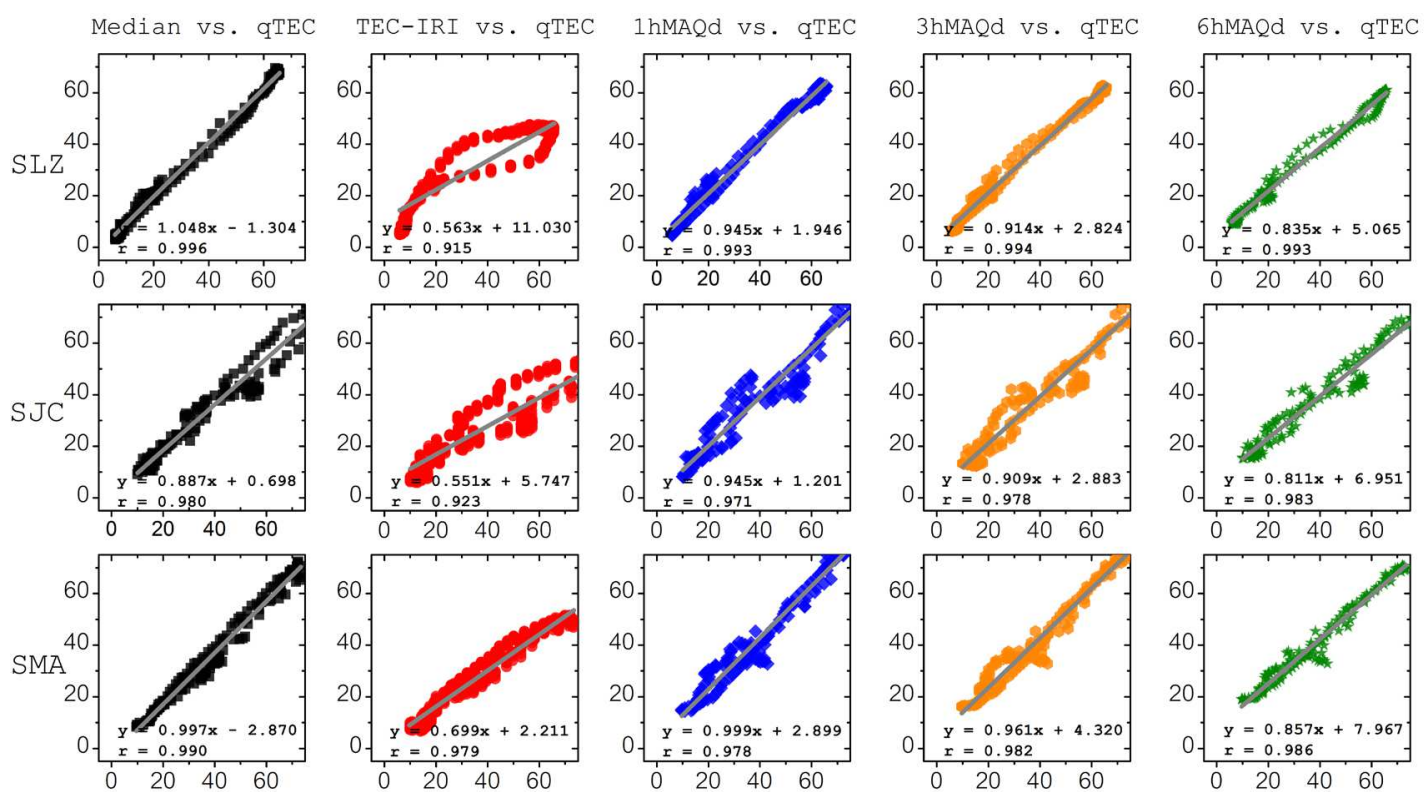

798

799

800

801

802

803

804

805

806

807

808 
811

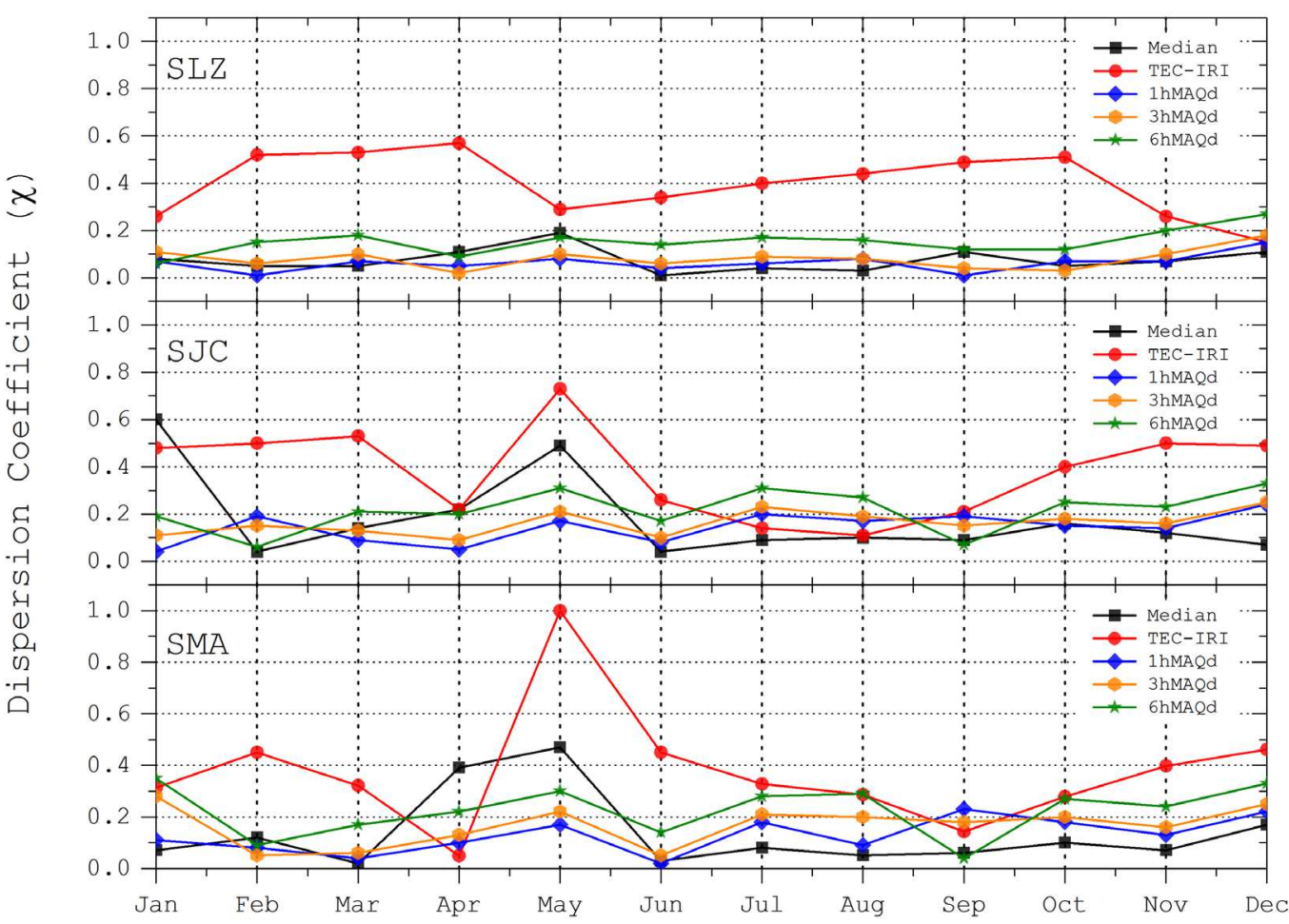

(a)

(b)

(c) 


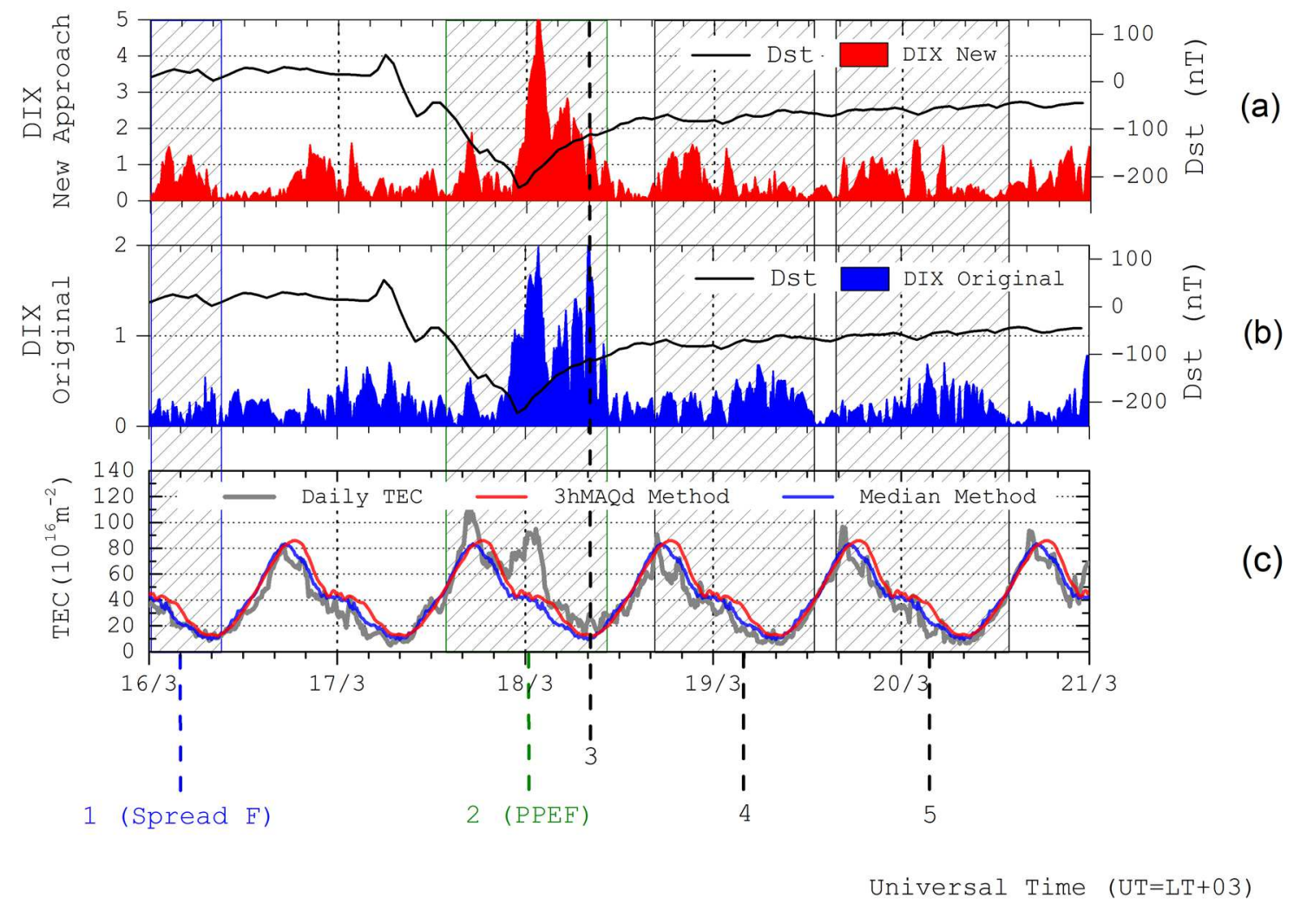



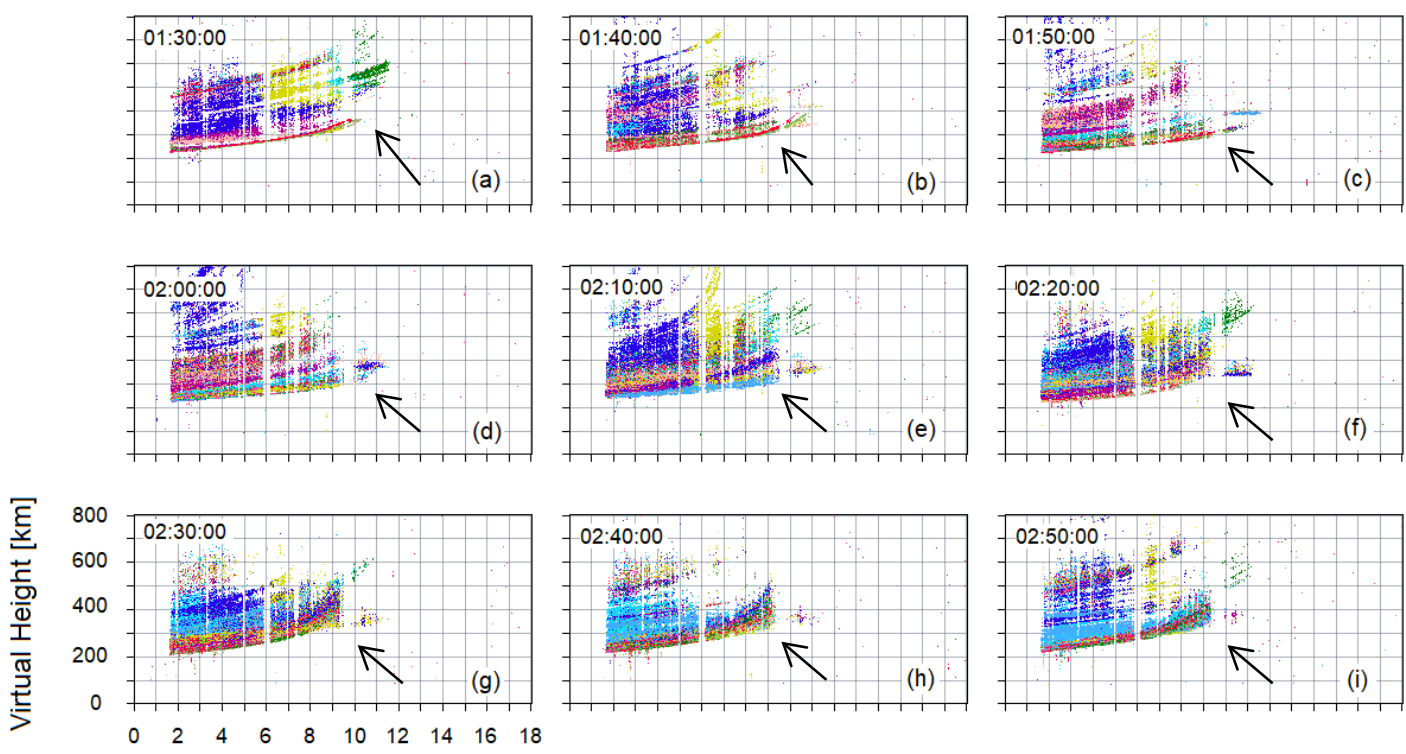

838

Frequency $[\mathrm{MHz}]$

CPA, 2015/03/16

839

840

841

842

843

844

845

846

847

848

849 
851

\begin{tabular}{lcccc}
\hline Location & \multicolumn{2}{c}{ Geographic } & Coordinates & \multicolumn{2}{c}{ Geomagnetic Coordinates } \\
\cline { 2 - 5 } & Lat. & Lon. & Lat. & Lon. \\
\hline São Luís (SLZ) & -2.53 & -44.30 & -3.79 & 27.03 \\
São José dos Campos (SJC) & -23.17 & -45.88 & -19.73 & 20.04 \\
Santa Maria (SMA) & -29.69 & -53.80 & -21.52 & 12.83 \\
\hline
\end{tabular}

852

853

854

855

856

857

858

859

860

861

862

863

864

865

866

867

Table 2 - 
868

\begin{tabular}{lccccc}
\hline & \multicolumn{5}{c}{ Dispersion Coefficient $(\chi)-$ Annual Average } \\
\cline { 2 - 6 } Location & Median & TEC-IRI & 1hMAQd & 3hMAQd & 6hMAQd \\
\hline SLZ & 0.08 & 0.40 & 0.06 & 0.08 & 0.15 \\
SJC & 0.18 & 0.38 & 0.14 & 0.16 & 0.22 \\
SMA & 0.14 & 0.39 & 0.13 & 0.17 & 0.23 \\
\hline
\end{tabular}

869 

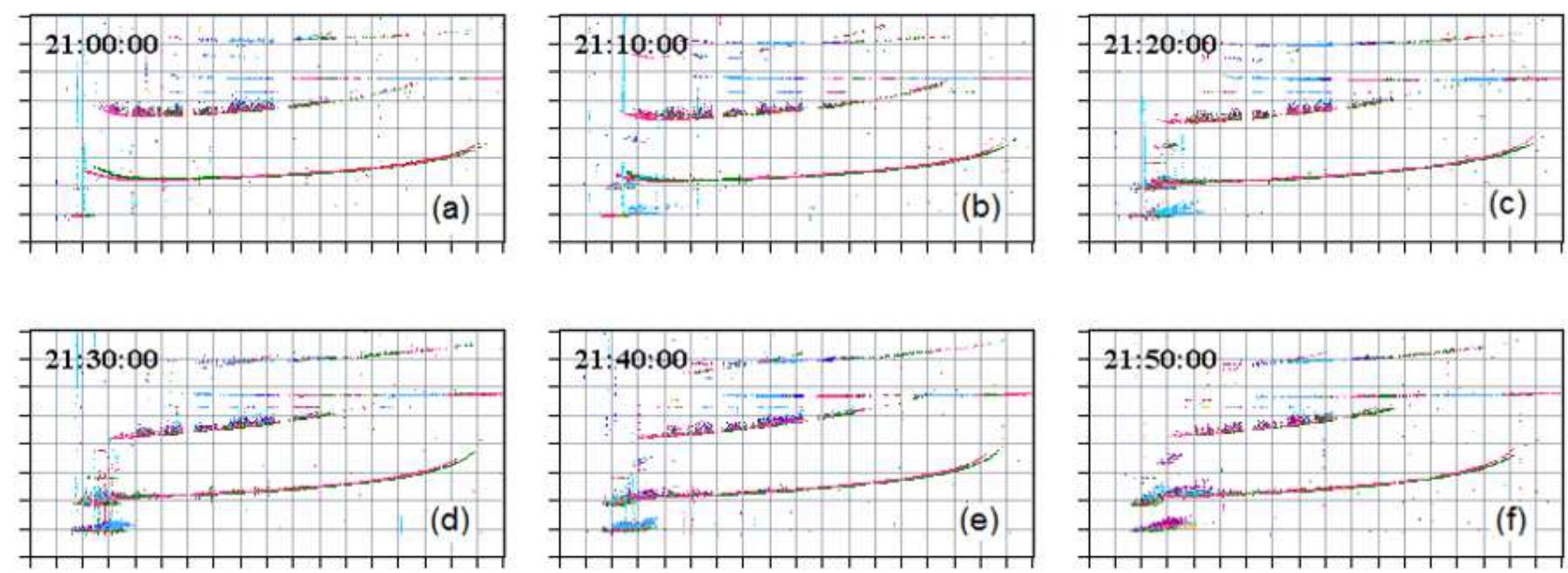

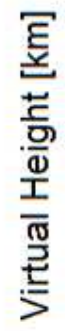
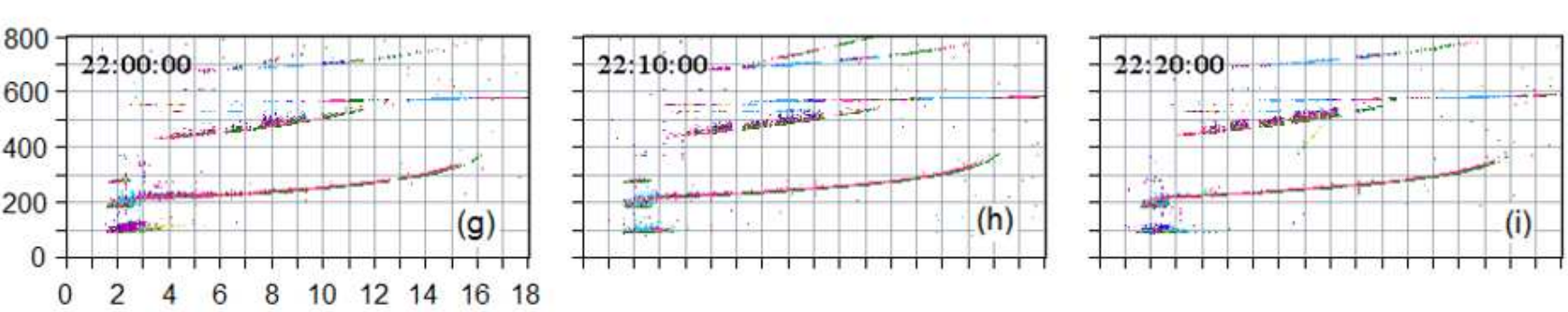

Frequency $[\mathrm{MHz}]$

CPA, 2015/03/14

Figure 1

Sequence of ionograms from 21:00 UT to 22:20 UT on March 14, 2015, demonstrating the absence of spread-F over Cachoeira Paulista. 


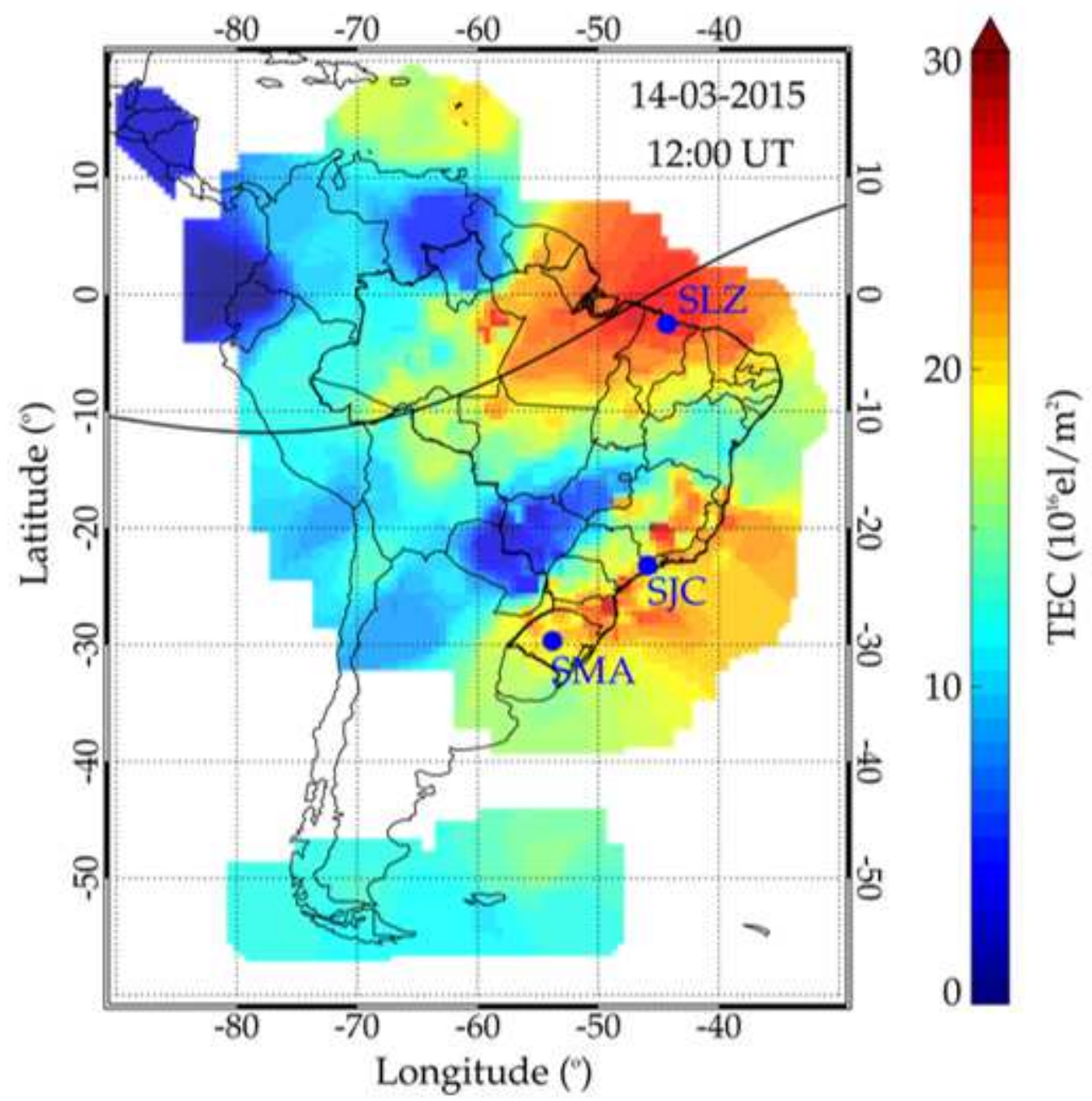

Figure 2

TEC map on 14 March, 2015 showing the geographic locations of the three TEC single-points used in this study: SLZ, SJC, SMS. 

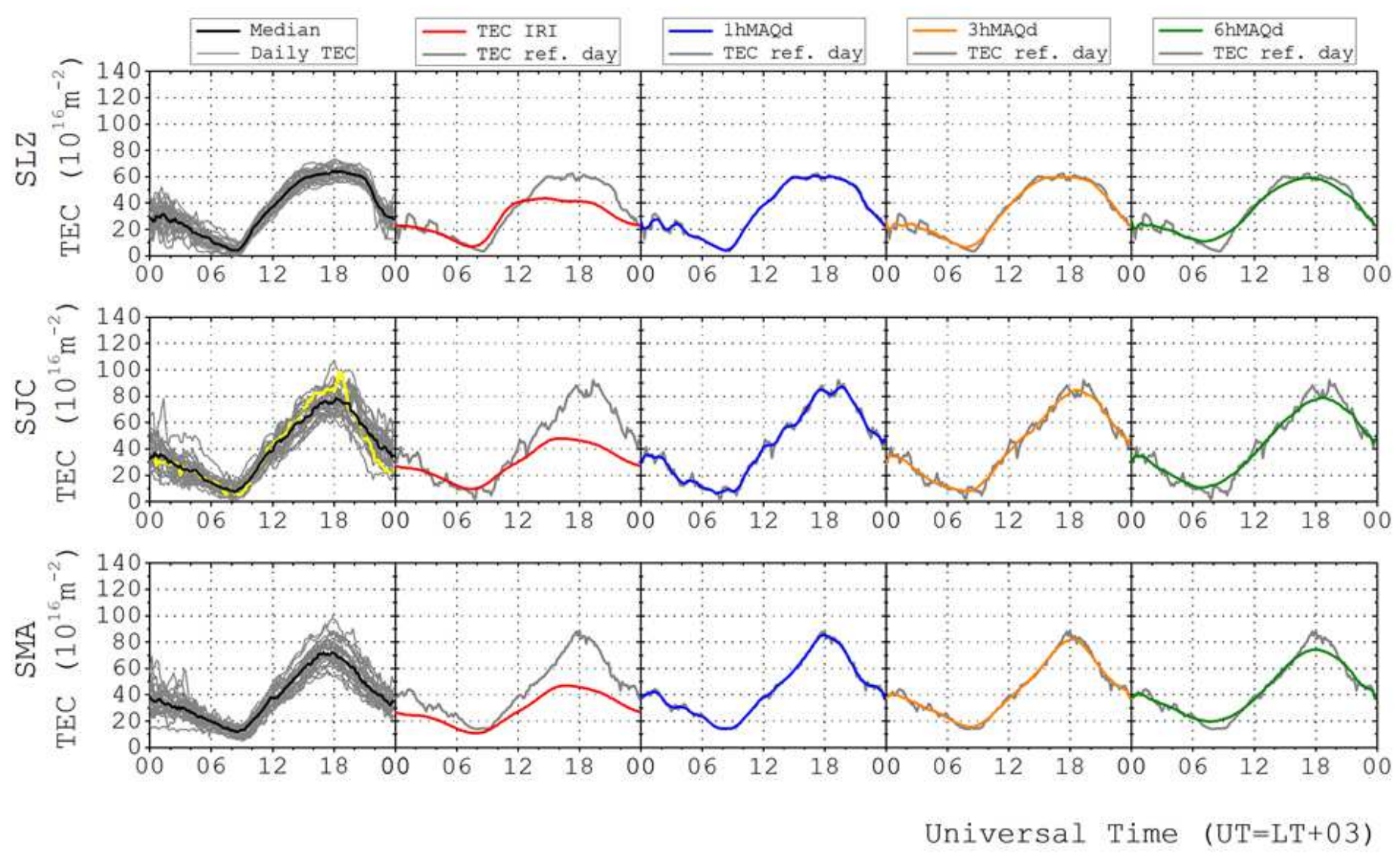

\section{Figure 3}

Time variation of non-perturbed TEC references calculated from each of the methods (black lines: monthly medians, red lines: TEC-IRI, blue lines: 1hMAQd, orange lines: 3hMAQd, and green lines: 6hMAQd), for the three TEC sites (SLZ, SJC, and SMA) on February 2015, from the TEC measurements (gray lines). 


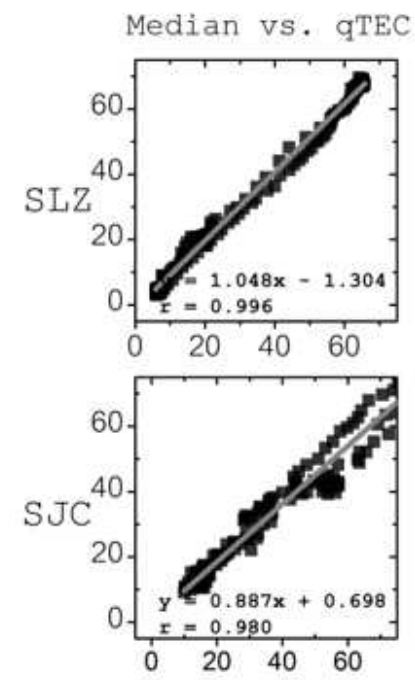

TEC-IRI vS. qTEC

1hMAQd vs. GTEC

3hMAQd vs. GTEC

6hMAQd vs. GTEC
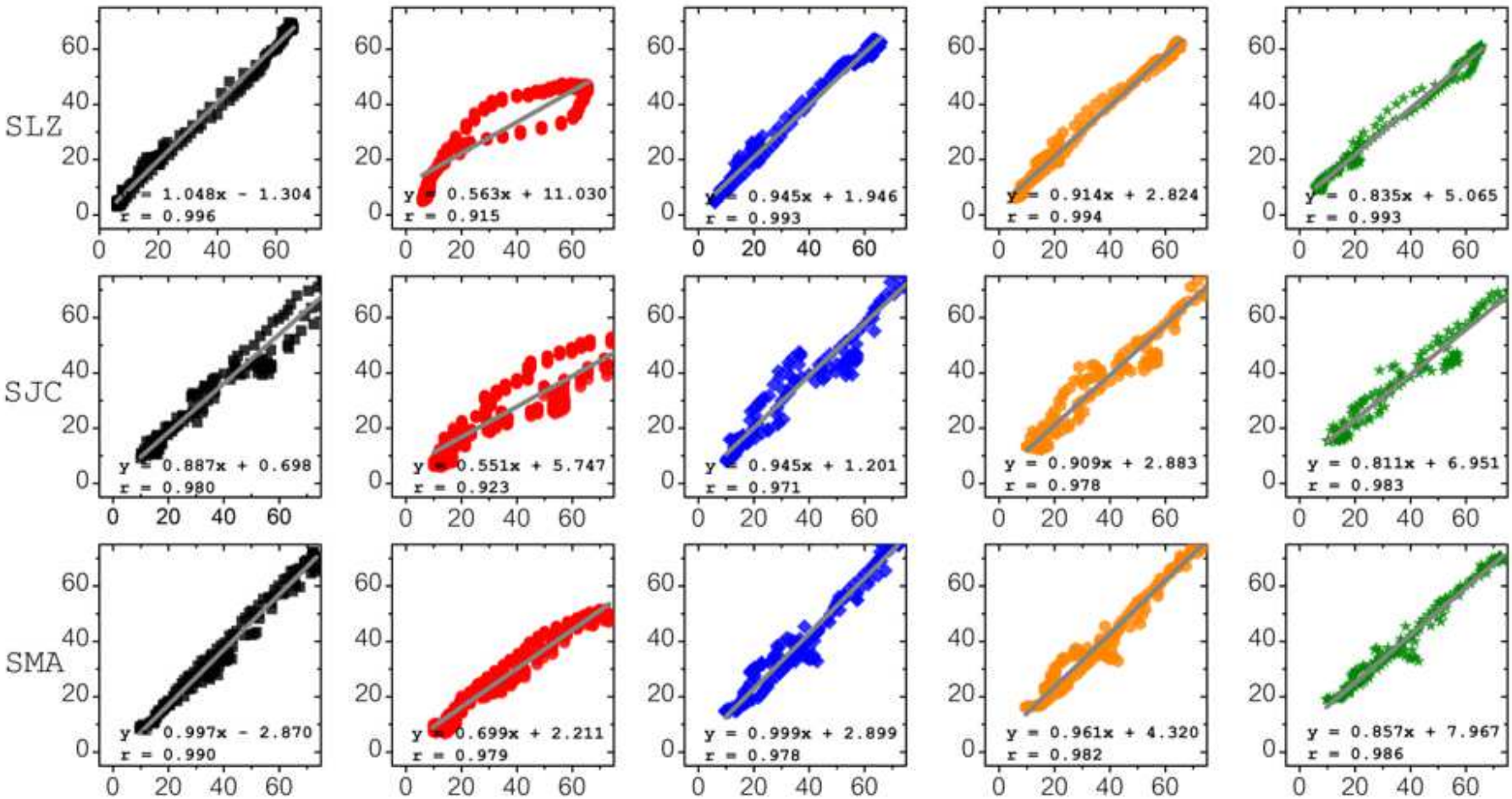

Figure 4

Scatter plots of the non-perturbed references calculated from the monthly medians (black symbols), TECIRI (red symbols), $1 \mathrm{hMAQd}$ (blue symbols), 3hMAQd (orange symbols), and 6hMAQd (green symbols) at (a) SLZ, (b) SJC , and (c) SMA against the qTEC values in March 2015, respectively. 


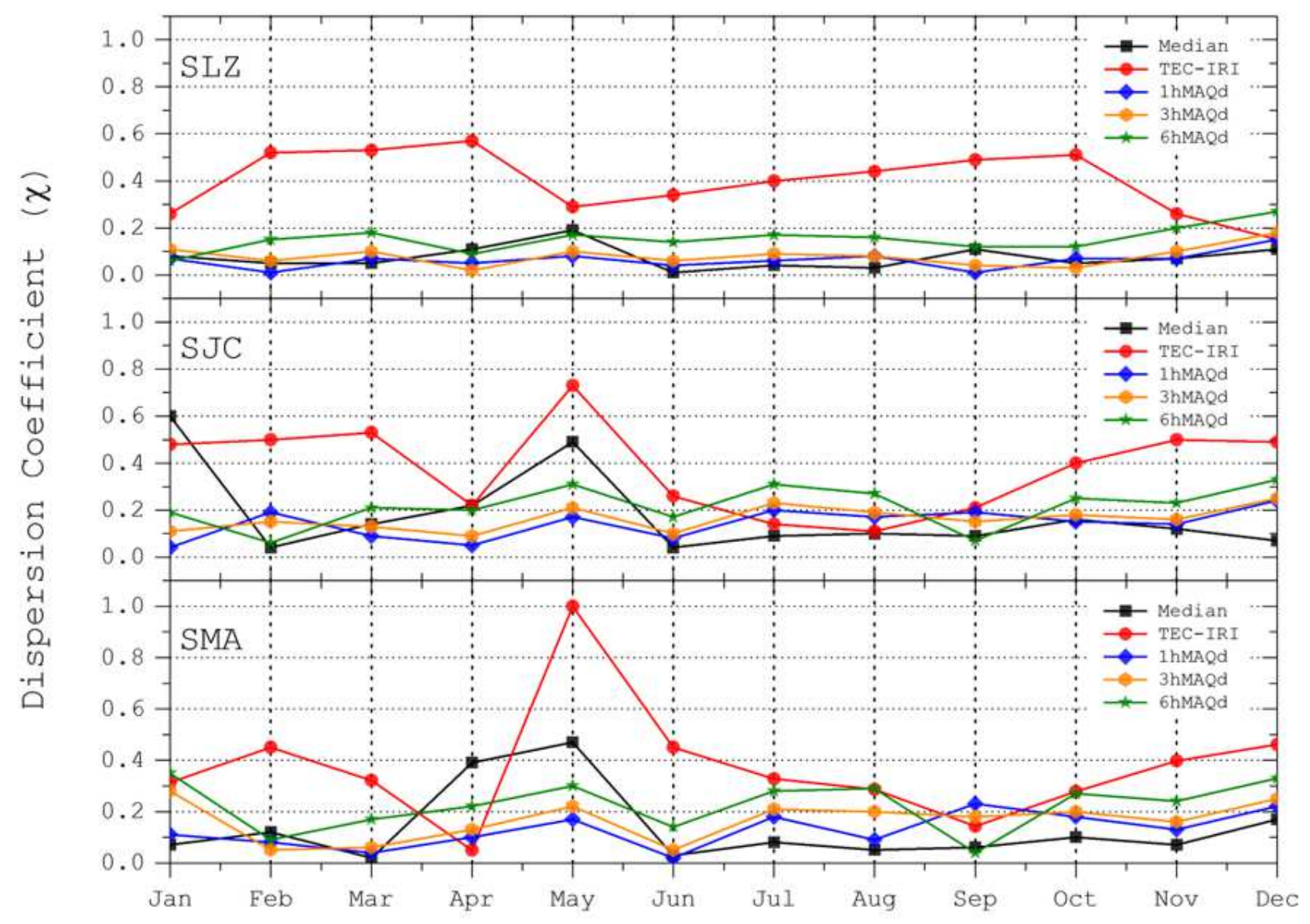

(a)

(b)

(c)

\section{Figure 5}

Annual variation of dispersion coefficient values related to the monthly medians (black squares), TEC-IRI (red cyrcles), 1hMAQd (blue diamonds), 3hMAQd (orange hexagons), and 6hMAQd (green stars) at (a) SLZ, (b) SJC, and (c) SMA during the year 2015. 


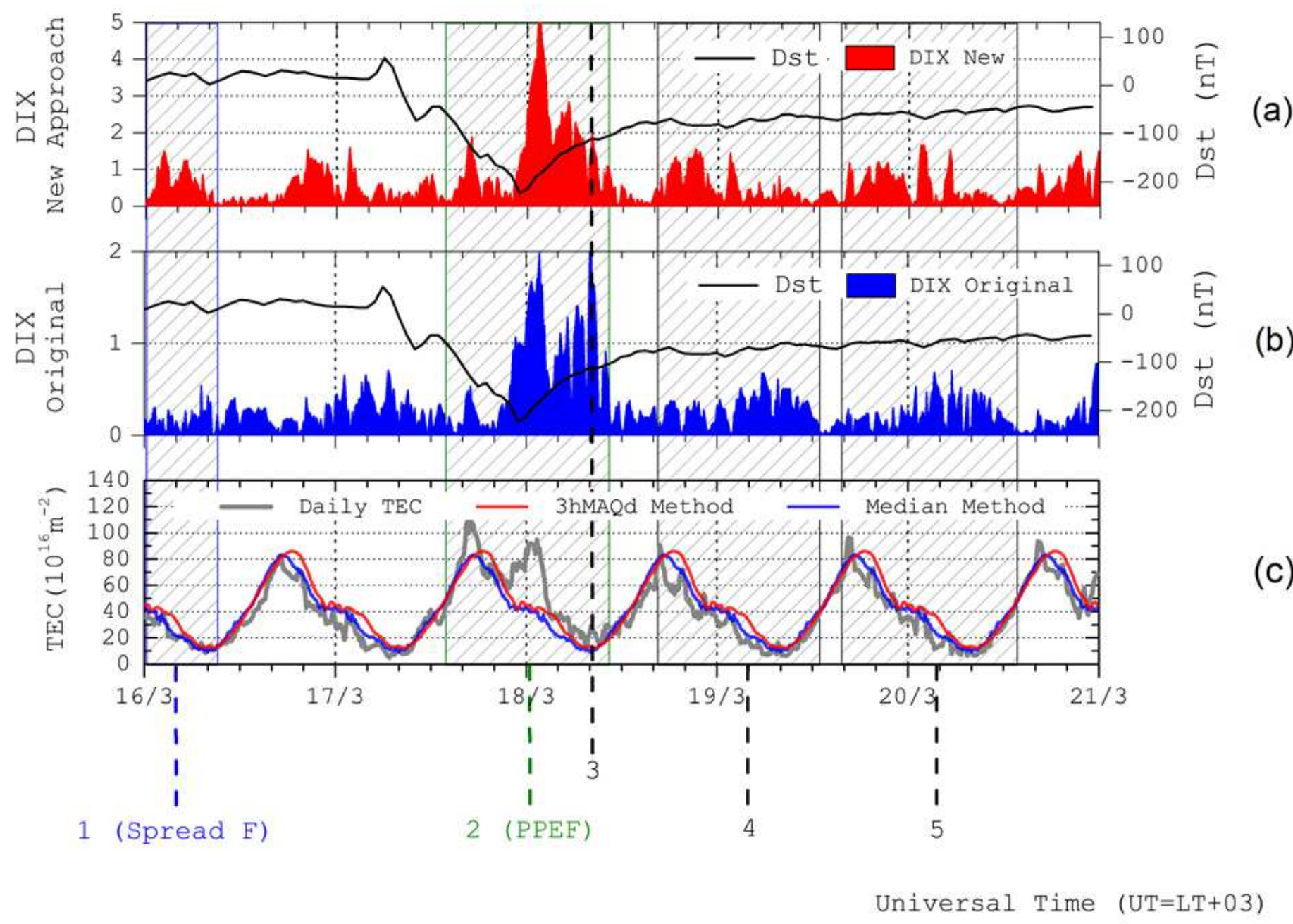

Figure 6

Time variation of (panel 'a') new DIX and (panel 'b') original DIX, superposed by the Dst index, and nonperturbed references (panel ' $c$ ') used for their calculation along with the daily TEC during the period around the St. Patrick's Day magnetic storm. 

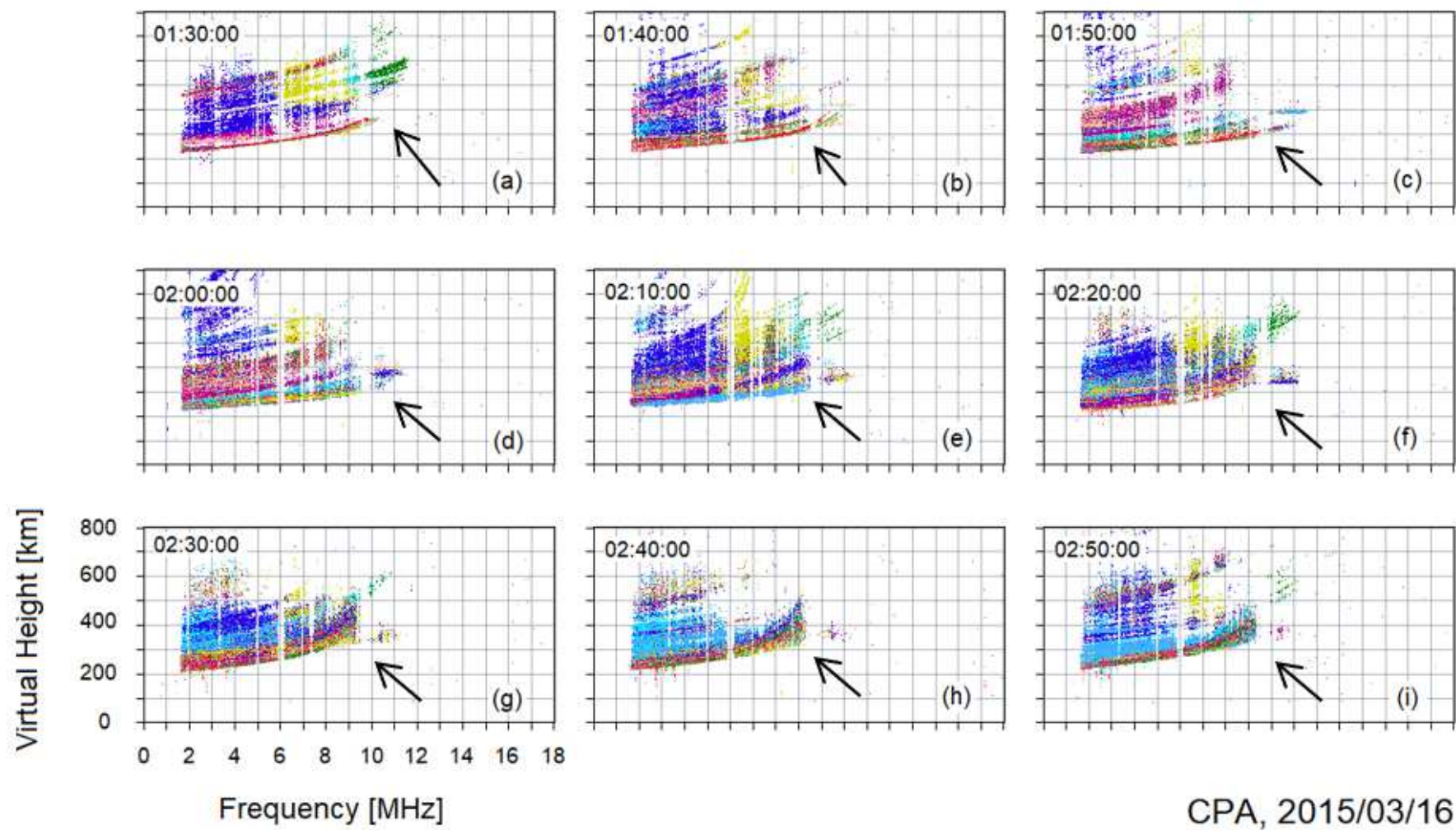

CPA, 2015/03/16

Figure 7

Sequence of ionograms from 01:30 UT to 02:50 UT on March 16, 2015, demonstrating the presence of spread-F over Cachoeira Paulista (same SJC observation point). Black arrows indicate spread of the signal.

\section{Supplementary Files}

This is a list of supplementary files associated with this preprint. Click to download.

- graphicalabstractimage.jpg 